\title{
Canadian Pain Society Conference \\ May 27 - 30, 2008, Victoria, British Columbia
}

\section{COMMUNITY PUBLIC EVENT TUESDAY, MAY 27, 2008}

\author{
6:30 PM - CHANGING PAIN CARE: THE BRITISH \\ COLUMBIA STRATEGY \\ 7:15 PM - DEVELOPMENT OF A PAIN CARE \\ EDUCATION STRATEGY FRAMEWORK
}

1

Chair: Janice Muir RN MSc, CNS Pain Management, Province Health Care, \& Assistant Clinical Professor, University of British Columbia, SON, Vancouver, British Columbia Speakers: Michael Negraeff MD FRCPC FFMANZCA, Lynne Young RN PhD

WORKSHOP OBJECTIVE:

AIM: To share with the participants the process of developing a coordinated Provincial pain care strategy across the continuum of care from birth to end-of-life including community engagement, provider engagement, model development including pain hotline and navigation center, provincial website development, chronic pain registry, optimal pain care in residential and acute care facilities, advocacy, as well as the development of a pain care education strategy framework.

Learning Objectives:

At the end of this 90 minute workshop, participants will be able to:

1. Understand the need for a coordinated provincial pain care strategy.

2. Describe pain care needs of the community and providers who try to provide pain care.

3. Discuss a provincial pain care model and the importance of cost avoidance. 4. Understand how working collaboratively with all the provincial health regions in key sub working groups can help with the development of a provincial pain care strategy business case.

5. Identify the key principles and strategies of a pain care education strategy framework

\section{$1 \mathrm{~A}$}

\section{CHANGING PAIN CARE: THE BRITISH COLUMBIA STRATEGY}

Michael Negraeff MD FRCPC FFMANZCA, Department of Anesthesiology, Pharmacology \& Therapeutics, Spine Program, Vancouver Coastal Health; Clinical Associate Professor, University of British Columbia, Faculty of Medicine, Vancouver, British Columbia

BRIEF DESCRIPTION: Pain is a resistant care issue across disciplines. Traditionally, education directed at specific health care professionals has been the strategy for catalyzing change in pain care practices. However, given that statistics on the presence of pain, both acute and chronic, have not changed substantively in the past two decades even given new medications, new technologies, and new assessment and management tools, an initiative is in process in British Columbia to address this resistant issue at the system level. This strategic initiative crosses disciplines, health regions, and health sectors. Within the overall strategy there are sub working groups concerned with developing strategic initiatives including the following: pain care education; model development including pain hotline and navigation center; website development; chronic pain registry; optimal pain care in residential and acute care facilities; and advocacy. In this workshop, presenters will provide an overview of the specific initiatives within the overall strategy and present the pain care education strategy.

\section{B \\ DEVELOPMENT OF A PAIN CARE EDUCATION STRATEGY FRAMEWORK}

Lynne Young RN PhD, Associate Professor, University of Victoria, School of Nursing, Victoria, British Columbia

BRIEF DESCRIPTION: The purpose of a pain care education framework is to meet the needs of patients, families/caregivers and health care providers to ensure evidence-informed care resulting in optimal pain care. A pain care education strategy framework provides a plan based on key principles and strategies. The education strategies may be stratified by setting (e.g. Primary Care, Community and Acute) and identified as either short or long term (greater than 6 months). The Provincial Pain Management Strategy Working Group and its various Sub Working Groups, individual(s) and other(s) are overseeing this education strategy framework. It is anticipated that this Provincial Pain Management Strategy Working Group will evolve into a standing provincial committee managing the longer-term aspects of the pain care education strategy. This presentation will outline the pain education strategy.

\section{PAIN EDUCATION DAY WEDNESDAY, MAY 28, 2008}

\section{2}

SEX-RELATED DIFFERENCES IN PAIN AND ANALGESIA

Chair: Donna Gramigna RN BSN CPNC

Clinical Nurse Educator, Vancouver Island Health Authority,

Regional Pain Program \& Surgical Ambulatory Clinics; President, British Columbia Operating Room Nurses Group, Victoria, British Columbia

Speaker: Rebecca M Craft PhD

Professor and Director of Experimental Training, Department of Psychology, Washington State University, Pullman, Washington BRIEF DESCRIPTION: Sex differences in pain and analgesia are widely reported, from laboratory experiments to epidemiological studies. A brief overview of sexual differentiation of pain and opioid analgesia will be provided, with emphasis on organizational and activational effects of gonadal steroid hormones on the opioid system.

\section{A}

AGE-RELATED CHANGES IN ARTHRITIS PAIN PROCESSING Chair: Donna Gramigna RN BSN CPNC

Clinical Nurse Educator, Vancouver Island Health Authority, Regional Pain Program \& Surgical Ambulatory Clinics; President, British Columbia Operating Room Nurses Group, Victoria, British Columbia

Speaker: \ason McDougall BSc PhD

Department of Physiology and Biophysics, University of Calgary, Calgary, Alberta

BRIEF DESCRIPTION: Pain perception is known to change with age. This presentation will explore the effect of age on peripheral pain-sensing mechanisms that have been revealed in animal models of arthritis. 


\section{9:00 AM - SESSION 101}

\section{3}

\section{UPDATE ON PERI-OPERATIVE PAIN MANAGEMENT}

Chair: Philip Peng MBBS FRCPC

Department of Anesthesia and Pain Management, Wasser Pain

Management Center, University Health Network and Mount Sinai

Hospital, Toronto, Ontario

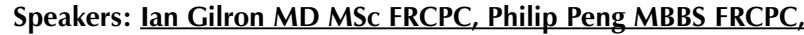

Ban Tsui MD MSc FRCPC

WORKSHOP OBJECTIVE: The objective of this workshop is to update the audience the current understanding of the regional anesthesia, anticonvulsants and Cox-2I in the mutli-modal approach of peri-operative pain management.

Learning Objectives:

1. Participants will be able to understand the mechanisms, efficacy and applications of the use of anticonvulsants as adjuvants in peri-opreative pain management.

2. Participants will learn the controversies of the role of NSAID, Cox-2I in bleeding, bone fusion, effects on cardiovascular, cerebrovascular, renal and gastrointestinal system in the peri-operative setting.

3. Participants will be able to understand the roles of regional anesthesia in perioperative pain management, especially the current improvement in technology, and understandings of outcome.

\section{A}

\section{THE ROLE OF ANTICONVULSANT DRUGS IN POST- OPERATIVE PAIN MANAGEMENT}

Ian Gilron MD MSc FRCPC

Departments of Anesthesiology, Pharmacology \& Toxicology,

Queen's University, Kingston, Ontario

BRIEF DESCRIPTION: Non-opioid adjuvant drugs are an important part of multimodal analgesia in the peri-operative period, and anticonvulsants are one of the adjuvants gaining popularity recently. The objective of the lecture is to discuss the mechanism, efficacy and application of the anticonvulsants in post-operative pain control.

\section{B}

\section{CONTROVERSIES OF USE OF NSAID AND COX-2 INHIBITORS IN PERI-OPERATIVE PERIOD \\ Philip Peng MBBS FRCPC}

Department of Anesthesia and Pain Management, Wasser Pain Management Centre, University Health Network and Mount Sinai Hospital, Toronto, Ontario

BRIEF DESCRIPTION: NSAID and Cox-2I are recommended for postoperative analgesia unless contraindicated. However, the potential effects on bleeding, bone fusion, cardiovascular, cerebrovascular, renal and gastrointestinal system remains controversial. The objective of the talk is to discuss the controversies based on the current evidence.

\section{C}

\section{UPDATE ON REGIONAL ANESTHESIA IN PERI-OPERATIVE PAIN CONTROI}

\section{Ban Tsui MD MSc FRCPC}

Department of Anesthesiology and Pain Medicine, Stollery Children's Hospital/University of Alberta Hospital, Edmonton, Alberta

BRIEF DESCRIPTION: Regional anesthesia is adopted increasingly in the peri-operative care of patient. This is related to the improvement of technology and techniques, better understanding of outcome and increased acceptability among surgeons and patients. The objective of this talk is to update the audience the expanding role of regional anesthesia in peri-operative pain management, especially in view of the current improvement in technology, techniques, and understandings of outcome.

\section{9:00 AM - SESSION 102}

\section{4}

\section{INTERPROFESSIONAL EDUCATION EXPERIENCE IN PAIN MANAGEMENT}

Chair: Brian Warriner

University of British Columbia Chair, Anaesthesia

Speakers: Karen L Hewson BScN MN, Susan Poulin BSc (Pharm)

FCSHP, Murray P Abrams BA Hons

WORKSHOP OBJECTIVE: The overall aim of this workshop will be to describe the research findings from a twelve week IPE Project in Pain management held within the Regina Qu'Appelle Health Region in Regina, Saskatchewan from September to November, 2007.

Learning Objectives:

At the conclusion of this workshop the participants will:

1. Be familiar with the background literature on undergraduate education in pain management as the rationale for the IPE Pain project.

2. Understand the P-CITE IPE project in pain management, including topics and teaching-learning strategies.

3. Examine the research findings of student perceptions of the IPE project in pain management

4. Observe a videotaped session of one of the project seminars.

5. Participate in small group discussions exploring the issues and challenges around sustainability of undergraduate interprofessional.

\section{$4 \mathrm{~A}$}

\section{NURSING}

Karen L Hewson BScN MN

College of Nursing, University of Saskatchewan, Regina,

Saskatchewan

BRIEF DESCRIPTION: The Interprofessional Education (IPE) Pain Management Project was funded by the Patient-Centered Interprofessional Education initiative (P-CITE) for Saskatchewan as part of the Interprofessional Education for Collaborative Patient-Centered Practice initiative (IECPCP) of Health Canada. P-CITE was established to support the development and implementation of quality interprofessional curricula and clinical experiences for health professional students. Ongoing evaluative reporting of project process and outcomes was undertaken to guide IPE best practices and promote sustainability of activities following the initial funding period. This workshop will describe the program content and teaching-learning strategies of the IPE project in Pain Management. Weekly seminars provided students with the opportunity to explore pain management topics including: current pharmacological approaches, pain assessment, pain in the elderly, cultural aspects of pain, addiction issues, and psychosocial pain interventions. Sessions were in keeping with P-CITE core themes of chronic disease in middle aged adults, elders in transition from acute to community care, and health in aboriginal communities. A combination of learning approaches were utilized including problem based learning, case-based discussions, expert guest presenters and collaborative student case presentations. The clinical component of the pain management project corresponded with the students existing practica in acute care, rehabilitation, and primary health care settings. The authors will present research findings concerning student perceptions of the IPE Pain Management project. Students completed questionnaires assessing various aspects of the IPE Pain Management project, as well as participated in a videotaped focus group on interprofessional education at the undergraduate level.

\section{B}

\section{PHARMACY}

Susan Poulin BSc (Pharm) FCSHP

Pharmacy Consultant, Regina Qu'Appelle Health Region, Regina, Saskatchewan

BRIEF DESCRIPTION: The Interprofessional Education (IPE) Pain Management Project was funded by the Patient-Centered Interprofessional Education initiative (P-CITE) for Saskatchewan as part of the 
Interprofessional Education for Collaborative Patient-Centered Practice initiative (IECPCP) of Health Canada. P-CITE was established to support the development and implementation of quality interprofessional curricula and clinical experiences for health professional students. Ongoing evaluative reporting of project process and outcomes was undertaken to guide IPE best practices and promote sustainability of activities following the initial funding period. This workshop will describe the program content and teaching-learning strategies of the IPE project in Pain Management. Weekly seminars provided students with the opportunity to explore pain management topics including: current pharmacological approaches, pain assessment, pain in the elderly, cultural aspects of pain, addiction issues, and psychosocial pain interventions. Sessions were in keeping with P-CITE core themes of chronic disease in middle aged adults, elders in transition from acute to community care, and health in aboriginal communities. A combination of learning approaches were utilized including problem based learning, case-based discussions, expert guest presenters and collaborative student case presentations. The clinical component of the pain management project corresponded with the students existing practica in acute care, rehabilitation, and primary health care settings. The authors will present research findings concerning student perceptions of the IPE Pain Management project. Students completed questionnaires assessing various aspects of the IPE Pain Management project, as well as participated in a videotaped focus group on interprofessional education at the undergraduate level.

\section{C}

\section{PSYCHOLOGY}

\section{Murray P Abrams BA Hons}

Graduate Student in Clinical Psychology, University of Regina, Regina, Saskatchewan

BRIEF DESCRIPTION: The Interprofessional Education (IPE) Pain Management Project was funded by the Patient-Centered Interprofessional Education initiative (P-CITE) for Saskatchewan as part of the Interprofessional Education for Collaborative Patient-Centered Practice initiative (IECPCP) of Health Canada. P-CITE was established to support the development and implementation of quality interprofessional curricula and clinical experiences for health professional students. Ongoing evaluative reporting of project process and outcomes was undertaken to guide IPE best practices and promote sustainability of activities following the initial funding period. This workshop will describe the program content and teaching-learning strategies of the IPE project in Pain Management. Weekly seminars provided students with the opportunity to explore pain management topics including: current pharmacological approaches, pain assessment, pain in the elderly, cultural aspects of pain, addiction issues, and psychosocial pain interventions. Sessions were in keeping with P-CITE core themes of chronic disease in middle aged adults, elders in transition from acute to community care, and health in aboriginal communities. A combination of learning approaches were utilized including problem based learning, case-based discussions, expert guest presenters and collaborative student case presentations. The clinical component of the pain management project corresponded with the students existing practica in acute care, rehabilitation, and primary health care settings. The authors will present research findings concerning student perceptions of the IPE Pain Management project. Students completed questionnaires assessing various aspects of the IPE Pain Management project, as well as participated in a videotaped focus group on interprofessional education at the undergraduate level.
9:00 AM - SESSION 103

\section{5}

\section{POLICIES \& OUTCOMES}

Chair: Brenda Lau MD FRCPC FFPMANZCA MMed (Pain Mgmt)

Surrey Memorial Hospital, Surrey, British Columbia

Speakers: Brenda Lau MD FRCPC FFPMANZCA MMed (Pain

Mgmt), Steven Helper MD FRCPC, James Francis MD, Pam Squire MD CCFP

\section{A}

\section{ACCREDITED PAIN MEDICINE FELLOWSHIP PROGRAMS AND THE NEED FOR STANDARDIZED PRACTICE \\ Brenda Lau MD FRCPC FFPMANZCA MMed (Pain Mgmt) \\ Surrey Memorial Hospital, Surrey, British Columbia}

The sub-specialty accreditation process in Canada will be compared with existing examples in Australia, USA and UK. The impact of accredited Pain Medicine fellowship programs on future practices will also be examined.

\section{B}

PUBLIC VS PRIVATE HEALTH CARE

Steven Helper MD FRCPC

Interventional Spine, False Creek Surgical Centre, Vancouver, British Columbia

\section{C}

\author{
BARRIERS TO PAIN CONTROL MANAGEMENT ACCESS - \\ THE FAMILY DOCTOR'S PERSPECTIVE \\ James Francis MD \\ Chronic Pain, Nanaimo Regional Hospital, Interdisciplinary Pain \\ Clinic, Nanaimo, British Columbia
}

\section{D}

OPIATES AND THE REGULATORS

Pam Squire MD CCFP

Clinical Assistant Professor, University of British Columbia; Lions Gate Hospital, North Vancouver, British Columbia

\section{9:00 AM - SESSION 104}

\section{6}

COMPLEMENTARY THERAPIES FOR PAIN CONTROL

Chair: Gerald Tevaarwerk BA MD FRCPC

Certificate in Endocrinology and Metabolism, Professor Emeritus, University of Western Ontario, Medical School in Endocrinology and Metabolism, Internal Medicine and Nuclear Medicine; Endocrinology and Metabolism Practice, Director of Continuing Medical Education, Victoria Medical Society, Victoria, British Columbia Speakers: Gerald Tevaarwerk BA MD FRCPC, Christopher Lam MD, Michael Boissevain PhD Rpsych (British Columbia and Alberta), Michael Rocheleau MD FRCPC, James Filbey MD FRCPC, Robert Banner MD CCFP FRCP AAPM CAPM 
6A

ALTERNATIVE AND SUPPLEMENTAL PAIN RELIEF PRACTICES: PLAUSIBILITY, EFFICACY ASSESSMENT, AND THE PLACEBO EFFECT

Gerald Tevaarwerk BA MD FRCPC

Certificate in Endocrinology and Metabolism, Professor Emeritus, University of Western Ontario, Medical School in Endocrinology and Metabolism, Internal Medicine and Nuclear Medicine; Endocrinology and Metabolism Practice, Director of Continuing Medical Education, Victoria Medical Society, Victoria, British Columbia

\section{B}

\section{ACUPUNCTURE FOR PAIN MANAGEMENT: SO WHAT'S NEW?}

Christopher Lam MD

Family Physician-Acupuncturist, Clinical Assistant Professor, Department of Family Practice, University of British Columbia; Affilitate, University of Victoria Island Medical Program, Victoria, British Columbia

\section{C}

\section{UPDATE ON PSYCHOLOGICAL TREATMENT FOR CHRONIC PAIN: MINDFULNESS BASED COGNITIVE THERAPY}

Michael Boissevain PhD Rpsych (British Columbia and Alberta) Private Practice and the Vancouver Island Health Authority Regional Pain Program, Victoria, British Columbia

\section{D}

\section{UPDATE ON PROLIFERATIVE THERAPY}

Michael Rocheleau MD FRCPC

Vancouver Island Health Authority, Medical Director Stroke Rehabilitation, Victoria General Hospital; Physician, Aberdeen Hospital, Queen Alexandra Hospital, Royal Jubilee Hospital Pain Clinic, Victoria, British Columbia

\section{$6 \mathrm{E}$}

\section{UPDATE ON BOTULINUM TOXIN IN PAIN MANAGEMENT} lames Filbey MD FRCPC

Physical Medicine and Rehabilitation, Electrodiagnostic Medicine (EMG / NCS), Clinical Assistant Professor, University of British Columbia, Vancouver, British Columbia

\section{F}

\section{NEW FRONTIERS: LASER THERAPIES IN PAIN MANAGEMENT}

Robert Banner MD CCFP FRCP AAPM CAPM

ABHM Department of Anesthesia and Perioperative Medicine, University of Western Ontario, St Joseph's Health Care, London, Ontario

BRIEF DESCRIPTION: Phototherapy, also known as low-intensity laser therapy (LILT), low-level laser therapy (LLLT) and photobiomodulation (PBM) has been used throughout Europe, Canada and Japan for over 30 years. The term laser (photo) biostimulation or "biostim" is also sometimes used, particularly in the United States.

A review of the literature will look at the evidence of efficacy for LLLT in a range of painful conditions. At the end of the presentation, it is hoped the audience will have a current understanding of this modality of treatment in painful conditions and its potential for use in their patient population. The speaker will have a laser device on hand to demonstrate its use to those interested.

\section{1:00 AM - PLENARY SESSION}

\section{7}

\section{THE STOP PAIN PROJECT}

Chair: Manon Choinière PhD

Department of Anesthesiology, Faculty of Medicine, University de Montréal, Montreal, Quebec

Speakers: Manon Choinière PhD, Mélanie Racine PhD(c), Denise Guerriere PhD

BRIEF DESCRIPTION: To share for the first time the results of STUDY I of the STOP-PAIN PROJECT with the Canadian pain community (researchers, students, clinicians, industry partners). This multicentre study was conducted in collaboration with several well-established pain facilities across Canada.

\section{A}

RESULTS DESCRIBING THE BIO-PSYCHO-SOCIAL PROFILE OF CANADIAN PATIENTS

Manon Choinière PhD

Department of Anesthesiology, Faculty of Medicine, University de Montréal, Montreal, Quebec

BRIEF DESCRIPTION: Dr Manon Choinière will present the portion of the results of the STOP-PAIN Project (Study I) which describe the biopsycho-social profiles of Canadian chronic pain patients $(\mathrm{N}=728)$ who had been waiting to be seen in 8 large, university-affiliated multidisciplinary pain treatment facilities across Canada. Pharmacological and nonpharmacological treatments of pain used by these patients will also be documented. Changes in pain severity and patients' well-being over a 3 -month period will be presented with a subgroup of 272 patients while they remained on a waiting list.

\section{B}

CHRONIC PAIN DIFFERENCES OBSERVED IN THE PRESENT STUDY

Mélanie Racine PhD(c)

Department of Psychology, Université du Québec à Montréal; Programme des sciences biomédicales, Faculté de medicine, Université de Montréal, Montreal, Quebec

BRIEF DESCRIPTION: Mrs Mélanie Racine $\mathrm{PhD}$ (c) will focus on the differences observed in the present study between women and men in terms of the characteristics of their chronic pain (intensity, impact, etc), their psychological well-being and their use of health care resources. Results of multivariate regression analysis used to assess the complex interrelationships between pain severity, depression, pain beliefs, coping skills and sociodemographic factors will also be presented as a function of sex.

\section{C}

\section{PUBLIC AND PRIVATE COSTS OF CARE FOR PATIENTS} WITH CHRONIC PAIN

Denise Guerriere PhD

Department of Health Policy, Management and Evaluation, Faculty of Medicine, University of Toronto, Toronto, Ontario

BRIEF DESCRIPTION: Dr Denise Guerriere will discuss the results of the economic analysis which focuses on the direct and indirect costs associated with chronic pain in a subgroup of 374 patients who participated in the STOP-PAIN Project. Using a multivariate regression model, the relationships between these costs and demographic variables, pain severity, and physical and emotional functioning will be presented. The economic portion of the study was conducted by a team in Toronto consisting of Dr Guerriere, Mr Brandon Zagorski MS, and Ms Emma Stafford-Coyte. 


\section{2:00 PM - SESSION 105}

\section{8}

UPDATE ON INTERVENTIONAL PAIN MANAGEMENT Chair: William N McDonald MD FRCPC, Clinical Professor, Dept Anesthesiology, Pharmacology and Therapeutics, University of British Columbia, St Paul's Hospital Pain Program, Vancouver, British Columbia

Speakers: Chris Honey MD DPhil FRCS, Stephan KW Schwarz MD

Dr med PhD FRCPC, Nelson Svorkdal, Evan Effa MD FRCPC,

Mark Matishak MD FRCSC, Steven Helper MD FRCPC

\section{A}

MOTOR CORTEX STIMULATION: INDICATIONS, TECHNIQUE AND OUTCOME

Chris Honey MD DPhil FRCS

Associate Professor of Neurosurgery, University of British

Columbia, Vancouver, British Columbia

\section{B}

PERIOPERATIVE INTRAVENOUS LIDOCAINE INFUSION Stephan KW Schwarz MD Dr med PhD FRCPC

Assistant Professor, Department of Anesthesiology, Pharmacology \& Therapeutics, The University of British Columbia; Director of Research, Department of Anesthesia, St Paul's Hospital, Vancouver, British Columbia

\section{C}

SPINAL CORD STIMULATION APPLICATION FOR ANGINA AND PVD

Nelson Svorkdal

\section{D}

INTERVENTIONAL PROCEDURES IN PALLIATIVE CARE Evan Effa MD FRCPC

Department of Anesthesia, University of Victoria, University of British Columbia; Vancouver Island Health Authority, Victoria, British Columbia

\section{E}

\section{DISC ARTHROPLASTY FOR DISCONGENIC PAIN}

Mark Matishak MD FRCSC

Chief of Surgery, Royal Columbian Hospital, New Westminster, British Columbia

\section{F}

RADIOFREQUENCY: CURRENT AND EMERGING APPLICATION IN PAIN MANAGEMENT

Steven Helper MD FRCPC

Interventional Spine, False Creek Surgical Centre, Vancouver, British Columbia

\section{2:00 PM - SESSION 106}

\section{9}

MANAGING PAIN IN THE MUSCULOSKELETAL OROFACIAL PAIN PATIENT

Chair: Sujay Mehta DMD

Orofacial Pain Clinic, University of British Columbia, Vancouver, British Columbia

Speakers: Sujay A Mehta DMD, Virginia Fenzl BSc PT,

Mike Racich DMD FAGD Dipl ABOP

WORKSHOP OBJECTIVE: While pain relief is considered a basic human right, pain in the orofacial region has been poorly appreciated and managed from a multidisciplinary model. Pain to the orofacial complex includes multiple diagnostic entities. While dental and temporomandibular joint pains tend to be the primary focus with these pain complaints, additional diagnostic entities need to be explored for definitive management. This workshop will introduce concepts related to orofacial pains with respect to differential diagnosis, physical medicine management for the orofacial musculoskeletal patient and clinical management for the temporomandibular joint disorder (TMD) patient.

Learning Objectives:

1. Differentiate the various diagnostic entities presenting as facial pain

2. Review types of orofacial pains masquerading as "TMJ" pain

3. Appreciate the importance of facial pain management in the chronic pain individual

4. Recognize the multi-disciplinary approach to the facial pain patient

\section{A}

\section{DIFFERENTIAL DIAGNOSIS OF OROFACIAL PAINS}

Sujay A Mehta DMD

Orofacial Pain Clinic, University of British Columbia, Vancouver, British Columbia

BRIEF DESCRIPTION: Orofacial pain encompasses a vast number of disorders and diseases related to the teeth and its surrounding structures. These pains could include dental pathology, salivary gland disorders, neurovascular pains, neuropathic pains as well as musculoskeletal disorders. This session focuses on the various types of pains masquerading as temporomandibular joint diagnoses. This session will review pain disorders presenting to a university-based clinic. An improved understanding to the various types of orofacial pains will further assist not only in diagnosis, but also with improved management. Improved appreciation of these concepts allows for more rational approach to pain management for the head and neck region.

Learning Objectives:

1. Understand the various types of pains presenting in the orofacial region

2. Understand the various pain entities that can mimic TMD pains

\section{B}

PHYSIOTHERAPY IN THE MULTIDISCIPLINARY APPROACH TO MANAGEMENT OF TMD

Virginia Fenzl BSc PT

Pitt Meadows Physiotherapy Clinic, Pitt Meadows,

British Columbia

BRIEF DESCRIPTION: Physiotherapists see patients presenting with pain and dysfunction. Included are patients who may have been diagnosed with TMD or more frequently those who have gone unrecognized. These patients have often only reported selective signs and symptoms that they feel are appropriate for the health care professional they are seeing. Failure to see these signs and symptoms collectively and to recognize their interdependence early results in adaptations that may promote chronicity and compromise treatment success.

Learning Objectives:

1. Identify $T M D$ and classify it as the primary, secondary or coexisting contributor to pain dysfunction. 
2. Offer an understanding of the interdependence of the neuro-musculo-skeletal system in the precipitation and or perpetuation of TMD.

3. Use the identification and understanding to develop an effective treatment plan that will result in a more successful outcome.

The participants will be able to recognize the dysfunctions related to TMD and identify patients that would benefit from including Physiotherapy in a multidisciplinary approach.

\section{C}

\section{CLINICAL MANAGEMENT OF TMD IN EVERYDAY PRACTICE \\ Mike Racich DMD FAGD Dipl ABOP}

\section{Private Clinical Practice, Vancouver, British Columbia}

BRIEF DESCRIPTION: Patients present to the dental office for reasons related to appearance, function and discomfort. All three areas must be in harmony for overall patient satisfaction. Over the last decade and a half our knowledge in these areas has escalated, especially in the field of orofacial pain and temporomandibular disorders (TMD). This evidence-based presentation will overview current concepts in TMD management. The learning objectives will be:

Learning Objectives:

1. Review diagnostic considerations

2. Define TMD: what it is and is not

3. Review management considerations

The participant thereby will be able to apply the presented basic concepts to their practices immediately to optimize their patients' oral health.

\section{2:00 PM - SESSION 107}

\section{0}

\section{A COMMUNITY-BASED CHRONIC PAIN SERVICE: WHAT HAVE WE LEARNED AND WHERE ARE WE GOING?}

Chair: Patricia Foster RN MSN

Manager, Comox Valley Nursing Centre/VIHA, Courtenay, British

Columbia

Speakers: Brenda Bouttell RN BSN, David Corman BSc Pharm, Diane Davies BEd MA RCC CHTP

\section{Workshop Objective:}

1. Provide current information about a community based CP program;

2. Explore the role of community development strategies in initiating and enhancing pain services within a primary health care setting;

3. Explore interdisciplinary roles with the CP team;

4. Highlight self-management, and in particular, stress management, as an important component of $\mathrm{CP}$ treatment.

Learning Objectives:

Participants will:

1. Explore how to identify opportunities within their own communities for developing CP services;

2. Gain insights into the client's experience of living with $\mathrm{CP}$ (hearing the client's voice);

3. Gain understanding of self-management as a important component of any $\mathrm{CP}$ service;

4. Explore key roles within a community based CP team;

5. Explore "bumps in the road" that offer opportunities for innovation and team growth.

\section{A}

COMMUNITY DEVELOPMENT: THE FOUNDATION FOR A COMMUNITY-BASED PAIN SERVICE

Brenda Bouttell RN BSN

Comox Valley Nursing Centre, Vancouver Island Health Authority, Victoria, British Columbia

BRIEF DESCRIPTION: The Comox Valley Nursing Centre has been at the forefront of community based chronic pain $(\mathrm{CP})$ services for the past
14 years. Community development strategies have led to collaborative partnerships between health care agencies and the private sector. This community based service, situated within a primary health care setting, is a now a foundation for a Regional Pain Program on Vancouver Island. Participants will have an opportunity to explore the journey from clinical committment to innovation and action.

\section{B}

A COMMUNITY PHARMACIST WITHIN A HEALTH AUTHORITY: A UNIQUE OPPORTUNITY FOR COMMUNITY OUTREACH

\section{David Corman BSc Pharm}

Cumberland Pharmacy, Vancouver Island Health Authority, Victoria, British Columbia

BRIEF DESCRIPTION: Chronic pain services benefit from an interdisciplinary approach. Pharmacists can play a key role in the assessment and management of CP. The workshop will explore the unique role of a community based pharmacist: outreach, assessment, education and community development. This role has provided an opportunity to build stronger links with family physicians.

\section{$10 \mathrm{C}$}

"GOOD VIBRATIONS": THERAPEUTIC RELAXATION PROGRAM FOR PERSONS WITH CHRONIC PAIN AND/OR ILLNESS

Diane Davies BEd MA RCC CHTP

Pacific Therapy and Consulting, Courtenay, British Columbia

BRIEF DESCRIPTION: Stress and anxiety are significant factors in the the life of those living with chronic pain. A key component of treatment is self-management, the informed and engaged client who takes an active role in their treatment. Relaxation and meditation skills can enhance a client's ability to cope with the day to day reality of living with CP. This workshop will highlight the benefits and components of a relaxation program.

\section{FOOTNOTES/REFERENCES:}

Calgary Health Region (October 2004). Regional Pain Program: Strategic Plan.

Comox Valley Nursing Centre (Feb 2006). Vancouver Island Health Authority Chronic Pain Stakeholders Meeting.

Davis S, O’Hanley G. (January 2007). Vancouver Coastal Health:

Regional Pain Strategy. Community Engagement Report.

(www.vch.ca/ce/docs/reports/07_01_pain.pdf)

Hanson RW (2006). Self-Management of Chronic Pain. Patient

Handbook. http://long-

beach.med.va/Our_Services/Patient_Care/cpmpbook/cpmpbook.html

\section{2:00 PM - SESSION 108}

\section{1}

\section{RISING TO THE CHALLENGE OF THE DIFFICULT PATIENT ENCOUNTER}

Chair: Chris Spanswick MB ChB FRCA

Calgary Health Region, Chronic Pain Centre, Calgary, Alberta Speakers: Lori Montgomery MD CCFP, Calgary Health Region Chronic Pain Centre, Calgary, Alberta

Chris Spanswick MB ChB FRCA Calgary Health Region, Chronic

Pain Centre, Calgary, Alberta

WORKSHOP OBJECTIVE: This interactive workshop will use a nonthreatening role play to allow health care providers to practice effective communication techniques. Providers will be invited to recall a difficult patient encounter, and role play that experience to learn new ways to approach these situations.

Learning Objectives:

Participants will

1. Learn to identify the physician factors in the difficult patient encounter, 
2. Understand the patient's motivations and reasons for challenging behaviours, and

3. Develop skills for managing the conflict that arises out of differing goals; to leave the patient encounter not just unscathed, but with a sense of accomplishment.

\section{4:45 PM - CANADIAN PAIN SOCIETY PAIN EDUCATION SURVEY RESULTS}

\section{2}

CANADIAN PAIN SOCIETY PAIN EDUCATION SURVEY: VETERINARIANS TOP THE LIST

Judy Watt-Watson RN PhD

University of Toronto, Lawrence S Bloomberg Faculty of Nursing,

Toronto, Ontario

\section{SCIENTIFIC PROGRAM DAY ONE THURSDAY, MAY 29, 2008}

\section{8:15 AM - KEYNOTE SPEAKER}

\section{3}

\section{THE EMERGING BIOPSYCHOSOCIAL MODEL OF A MALE} CHRONIC PELVIC PAIN SYNDROME

Chair: Brian Cairns PhD RPh

Associate Professor \& Canada Research Chair, Faculty of Pharmaceutical Sciences, University of British Columbia, Vancouver, British Columbia

Speaker: Dean A Tripp PhD

Associate Professor, Departments of Psychology, Anesthesiology and Urology, Queen's University, Kingston, Ontario; 2008 CPS Early Career Award Winner

BRIEF DESCRIPTION: Chronic Prostatitis / Chronic Pelvic Pain Syndrome (CP/CPPS) is a prevalent and life-disrupting condition thought to primarily impact men aged $30-50$ years. Our NIH-sponsored research team has forged new directions in urological research by examining the determinants of pain, disability, quality of life, and sexual functioning in North American CP/CPPS samples using a biopsychosocial framework. Recently, we have again extended this body of research by examining the epidemiology and impact of such pain associated symptoms in younger North American and African males (16-19 years). These studies and future avenues for research will be reviewed in this address.

\section{0:00 AM - PLENARY SESSION 201}

\section{4}

\section{LIFESPAN FACTORS THAT PLAY A ROLE IN PREDISPOSITION TO CHRONIC PAIN}

Chair: Serge Marchand PhD

Director of Pain Research, Université de Sherbrooke, Faculty of Medicine, Neurosurgery, Sherbrooke, Quebec

Speakers: KJS Anand MBBS DPhil FAAP FCCM FRCPCH, Dan Buskila MD, Serge Marchand PhD

BRIEF DESCRIPTION: Several factors have been identified as significant contributors to the development and persistency of some chronic pain conditions. Among these factors, early life nociceptive stimulations and genetic predispositions are playing important roles. During this conference, Dr Anand will review the epidemiology of pain in neonates, cellular changes in the brain following acute or inflammatory pain, as well as mechanisms of how these changes cause long-term changes in brain function and behavior. Dr Buskila will present news evidences on how a genetically predisposed individual to a host of environmental stressors is presumed to lead to the development of widespread pain such as in fibromyalgia. Finally, Dr Marchand will present some results on how several factors such as early pain experience, sex hormones and aging are affecting the efficacy of endogenous pain modulation mechanisms and may lead to a predisposition for neurogenic chronic pain conditions. The speakers will discuss the scientific and clinical implication of these factors.

\section{A}

PAIN IN NEONATES: LONG-TERM CHANGES IN BRAIN FUNCTION \& BEHAVIOR

KIS Anand MBBS DPhil FAAP FCCM FRCPCH

Morris \& Hettie Oakley Endowed Chair of Critical Care Medicine, Professor of Pediatrics, Anesthesiology, Pharmacology,

Neurobiology \& Developmental Sciences, Director, Pain Neurobiology Laboratory, Member, Board of Directors, ACH Research Institute, Department of Pediatrics, University of Arkansas for Medical Sciences, Little Rock, Arkansas, USA

\section{B}

\section{GENETIC PREDISPOSITIONS TO THE DEVELOPMENT OF WIDESPREAD PAIN}

Dan Buskila MD

Department of Medicine $H$, Soroka Medical Center and Faculty of Health Sciences, Ben Gurion University, Beer Sheva, Israel

\section{C}

THE ROLES OF EARLY PAIN EXPERIENCE, SEX HORMONES AND AGING ON ENDOGENOUS PAIN MODULATION DEFICITS

Serge Marchand PhD

Director of Pain Research, Université de Sherbrooke, Faculty of Medicine, Neurosurgery, Sherbrooke, Quebec

$$
\text { 10:00 AM - SESSION } 202
$$

\section{5}

PAIN-RELATED ANXIETY AND FEAR AS KEY FACTORS OF THE PAIN EXPERIENCE: NEW RESEARCH INTO THE DEVELOPMENT, MAINTENANCE, AND TREATMENT OF PAIN

Chair: R Nicholas Carleton MA

The Anxiety and Illness Behaviour Laboratory, University of Regina, Regina, Saskatchewan

Speakers: $\mathrm{R}$ Nicholas Carleton MA, Margo C Watt PhD, loel Katz PhD, Gordon IG Asmundson PhD

BRIEF DESCRIPTION: Understanding how pain-related anxiety and fear impact and interact with the development and treatment of pain has become a primary focus of an increasing number of researchers. This symposium presents new research that contributes pieces to the puzzle of pain within the context of existing psychological knowledge. Carleton and colleagues begin with a review of the current fear avoidance models and evidence that suggests fear of pain is pervasive across anxiety and depressive disorders. Thereafter, Watt and colleagues provide evidence that treating anxiety sensitivity - the fear of somatic sensations related to anxiety - can reduce fear of pain, implying a facilitating effect for recovery. Using prospective longitudinal data, Katz then presents evidence for furthering our growing understanding of the overlap/interface between pain and clinically significant fear and anxiety. Finally, Asmundson and colleagues present biophysiological data that the pain experience, when characterized by pain-related negative emotionality, may be associated with dysregulated sympathetic discharge when people are exposed to physical discomfort. Together these presentations provide further support for a multidimensional biopsychosocial model for understanding and treating pain. A discussion of 
the implications and directions for future research follows the research presentations.

Learning Objectives:

1. To learn more about the relationship between psychological variables and the development, maintenance, and treatment of pain.

2. To learn more about possible interactions between the autonomic nervous system, cognitive factors underlying anxiety, and pain.

3. To learn more about the interaction between trauma and pain.

\section{A}

EVALUATING FEAR OF PAIN ACROSS ANXIETY AND DEPRESSIVE DISORDERS: RESPONSE PATTERNS TO THE PASS-20

R Nicholas Carleton $\mathrm{MA}^{1}$, Gordon JG Asmundson $\mathrm{PhD}^{1}$, Martin M Antony PhD $^{2,3}$, Randi E McCabe PhD $^{3}$

${ }^{1}$ The Anxiety and Illness Behaviour Laboratory, University of Regina, Regina, Saskatchewan

${ }^{2}$ Department of Psychology, Ryerson University, Toronto, Ontario ${ }^{3}$ Anxiety Treatment and Research Centre, St Joseph's Healthcare, and Department of Psychiatry and Behavioural Neurosciences, McMaster University, Hamilton, Ontario

Current fear anxiety avoidance models include fear of pain as a key diathetic variable in the development and maintenance of chronic pain (Asmundson et al., 2004). Although seemingly specific to chronic pain, researchers (Asmundson \& Carleton, 2005; in press) have also suggested that fear of pain may be a pervasive vulnerability factor across several disorders. In particular, the more general construct of pain-related anxiety seems to share several elements with the fundamental fears as described by Riess (1991) and Taylor (1993). The purpose of the present investigation was to assess self-report levels of pain-related anxiety (Pain Anxiety Symptoms Scale - Short Form; PASS-20; McCracken \& Dhingra, 2002) across several anxiety and depressive disorders and to compare those levels to non-clinical and chronic pain samples. Participants consisted of a clinical sample ( $n=454 ; 64 \%$ women) from the Anxiety Treatment and Research Centre at St. Joseph's Healthcare in Hamilton, Ontario. Primary diagnoses included depressive disorders (6\%), panic disorder (26\%), social anxiety disorder (30\%), obsessive-compulsive disorder (19\%), and generalized anxiety disorder (11\%). Group comparisons were made using analysis of variance and a series of $t$-tests were used to compare each group to published scores for non-clinical (Abrams et al., in press) and chronic pain samples (McCracken \& Dhingra, 2002). The results suggest that painrelated anxiety is generally comparable across anxiety and depressive disorders; moreover, pain-related anxiety was typically higher $(\mathrm{p}<.01)$ with this clinical sample relative to the non-clinical sample and often comparable to the chronic pain sample. Implications and directions for future research are discussed.

\section{$15 B$}

\section{A BRIEF COGNITIVE-BEHAVIORAL APPROACH TO REDUCING ANXIETY SENSITIVITY DECREASES PAIN- RELATED ANXIETY}

Margo C Watt PhD ${ }^{1,2}$, Sherry H Stewart PhD ${ }^{2,3}$, Marie-Josée Lefaivre $\mathbf{B A}^{2}$, Lindsay $\mathbf{S}$ Uman $\mathbf{B A}^{2}$

${ }^{1}$ Department of Psychology, St Francis Xavier University, Antigonish ${ }^{2}$ Department of Psychology, Dalhousie University, Halifax, Nova Scotia

${ }^{3}$ Department of Psychiatry, Dalhousie University, Halifax, Nova Scotia

Anxiety sensitivity (AS) is an individual difference variable characterized by a fear of arousal-related sensations. High AS is a known cognitive risk factor for the development of anxiety and related disorders and, more recently, has been linked to pain disorders. The present study was guided by the hypothesis that a brief cognitive behavioral therapy (CBT) intervention designed to reduce AS levels might also result in a decrease in anxiety related to pain sensations. The brief CBT was conducted in small group format. Participants were female undergraduates selected to form high and low AS groups, according to their scores on the Anxiety Sensitivity Index (ASI; Peterson \& Reiss, 1992). Participants were randomly assigned to participate in 3 one-hour sessions of either brief CBT (i.e., psycho-education, cognitive restructuring, and physical exercise interoceptive exposure) or a control group seminar (discussion about psychology ethics). Immediately prior to and following the intervention, participants completed the 20-item Pain Anxiety Symptoms Scale (PASS-20). Consistent with hypothesis, results revealed a 3-way interaction between AS group, intervention condition, and time on PASS-20 total scores. Only participants with high pre-morbid levels of AS assigned to the CBT condition showed a significant reduction in scores on the PASS-20 from preto post-treatment. Implications for improving CBT approaches for pain disorders are discussed.

\section{C}

CORRELATES AND PREDICTORS OF PAIN DISABILITY AND POSTTRAUMATIC STRESS DISORDER SYMPTOMS (PTSS) BEFORE AND AFTER MAJOR SURGERY

loel Katz $\mathrm{PhD}^{1,3}$, Valery Kleiman MSc ${ }^{1}$, Gordon Asmundson $\mathrm{PhD}^{2}$, Eileen Halket $\mathrm{RN}^{3}$

1Department of Psychology, York University, Toronto, Ontario

${ }^{2}$ The Anxiety and Illness Behaviour Laboratory, University of Regina, Regina, Saskatchewan

${ }^{3}$ Department of Anesthesia and Pain Management, Toronto, Ontario

Every chronic pain was, at one time, acute. Yet not all pains become chronic. Regardless of the cause(s) of pain, the majority of people recover uneventfully and do not go on to develop chronic pain. However, in the case of chronic post-surgical pain (CPSP), certain procedures are followed by an alarmingly high rate of chronic pain and discomfort. Prevalence rates between $30 \%$ and $70 \%$ have been reported years after surgery for arm pain after axillary node dissection for breast cancer, post-mastectomy scar pain, post-amputation phantom limb pain, and post-thoracotomy chest wall pain. What factors are responsible for the transition of acute postoperative pain to chronic, intractable, pathological pain? Is it something about the pain per se or the person in pain? We do not have an answer to these important questions but recent evidence points to a complex and poorly understood developmental process involving biological, psychological and social-environmental factors interacting across the pre-operative, intra-operative, post-operative periods. Dr Katz's presentation will focus on the cognitive and emotional factors that are associated with poor adaptation to surgery and that predict pain disability one year later. Preliminary evidence will be presented for a construct termed pain traumatization which describes the anxiety-related psychological and emotional reactions, as well as behavioral responses, to pain that resemble PTSS. Data will also be presented from a prospective study of patients after thoracotomy in which heightened preoperative emotional numbing predicted pain disability 12 months later even after controlling for preoperative pain disability, 12 month pain intensity and 12 month PTSS. Taken together, these data help to explain some of the variance in the development of CPSP and disability, but we are a long way from being able to predict who will recover uneventfully and who will go on to develop persistent pain.

\section{D}

\section{IS THE AUTONOMIC NERVOUS SYSTEM COMPROMISED IN PATIENTS WITH CHRONIC MUSCULOSKELETAL PAIN AND DOES NEGATIVE EMOTIONALITY PLAY A ROLE?}

\section{Gordon IG Asmundson PhD, R Nicholas Carleton MA}

The Anxiety and Illness Behaviour Laboratory, University of Regina, Regina, Saskatchewan

Autonomic nervous system (ANS) dysregulation in acute and chronic musculoskeletal pain has received little empirical scrutiny. In a related investigation, Rainville et al. (2005) used hypnosis to alter mood, perceived pain unpleasantness, and severity of pain induced in healthy participants. Their results indicated that increases in negative mood and pain unpleasantness were positively associated with changes in heart rate variability. This suggests that pain-related emotion impacts ANS responsivity. We have recently 
completed an extensive investigation of ANS dysregulation in patients with acute musculoskeletal pain $(n=12)$, chronic musculoskeletal pain $(n=33)$, and healthy controls $(n=30)$ using a variety of physiologic tasks designed to evoke measurable, bi-directional ANS responses. Preliminary analyses indicate no between-group differences with regard to tasks that augment vagal tone (i.e., Valsalva, voluntary breath hold); however, chronic musculoskeletal pain patients exhibited increased sympathetic activity relative to controls on tasks designed to induce rapid vagal withdrawal followed by sympathetic discharge (i.e., cold pressor, $t(60)=2.05, \mathrm{p}<.05$, and static exercise, $t(61)=$ $1.67, \mathrm{p}<.05)$. They also exhibited greater pain-related fear, greater fear of anxious arousal, and depressed mood relative to patients with acute musculoskletal pain and healthy controls. Accordingly, the experience of chronic musculoskeletal pain, characterized by pain-related negative emotionality, may be associated with dysregulated sympathetic discharge in response to discomforting physiologic challenges. Results will be discussed in the context of Norton and Asmundson's (2003) amended fear-avoidance model of chronic musculoskeletal pain.

10:00 AM - SESSION 203

\section{6}

\section{ABOVE AND BEYOND THE WHO LADDER - A MULTIDISCIPLINARY APPROACH FOR MANAGING REFRACTORY CANCER PAIN}

Chair: Catherine Smyth MD PhD FRCPC

Department Anesthesiology, The Ottawa Hospital; Assistant Professor, University of Ottawa; Medical Director, The Ottawa Hospital Pain Clinic, Ottawa, Ontario Speakers: Virginia Jarvis RN RM BScN MPC, Palliative Nurse Specialist, The Ottawa Hospital Cancer Centre, Ottawa, Ontario, Edward / Fitzgibbon MD MSc CCFP, Associate Professor, University of Ottawa; Medical Director, Palliative Care Program, The Ottawa Hospital, Ottawa, Ontario, Catherine Smyth MD PhD FRCPC, Department Anesthesiology, The Ottawa Hospital; Assistant Professor, University of Ottawa; Medical Director, The Ottawa Hospital Pain Clinic, Ottawa, Ontario

WORKSHOP OBJECTIVE: This workshop will review and discuss The Ottawa Hospital's rationale for its multidisciplinary approach for managing refractory cancer pain.

Learning Objectives:

1. To review the medical literature and institutional experience on the use of such parenteral medications as ketamine and lidocaine.

2. To review the basis in the literature for utilizing interventional techniques and the hospital's experiences with spinal and epidural catheters, regional nerve block catheters and neurolytic block techniques.

3. To discuss the practical aspects of managing refractory cancer patients with regards to: discharge planning, care in the community, and follow-up.

\section{A}

\section{ABOVE AND BEYOND THE WHO LADDER}

\section{Virginia Jarvis RN RM BScN MPC}

Palliative Nurse Specialist, The Ottawa Hospital Cancer Centre, Ottawa, Ontario

This presentation will focus on the challenges and benefits of providing safe and competent care to patients who require analgesia above and beyond the WHO Pain Ladder. In doing so, we will review The Ottawa Hospital's approach for treating patients whose pain is not controlled by utilizing the WHO Pain Ladder. Surveys indicate that as many as $10-14 \%$ of cancer patients may not be controlled by the WHO Pain Ladder. This is a significant problem and will only worsen as survival periods increase and the number of Canadians diagnosed with cancer grows. The Ottawa Hospital Cancer Centre sees an average of 650 patients per day. In a recent symptom prevalence survey conducted in the outpatient department of the Cancer Centre, $31.5 \%$ of patients reported moderate pain $(>4 / 10)$ while $11 \%$ reported severe pain $(>7 / 10)$.
Part of the challenge to providing safe and competent care for patients who are above the WHO Pain Ladder is the implementation of 'Just in Time' education, as well as the development of policies and procedures for allaying staff anxiety and enabling a smooth transition to community care.

\section{$16 B$}

ABOVE AND BEYOND THE WHO LADDER

Edward / Fitzgibbon MD PhD FRCPC

Associate Professor, University of Ottawa, Medical Director, Palliative Care program, The Ottawa Hospital, Ottawa, Ontario In addition to those patients whose pain is refractory to the WHO Pain Ladder are those that have significant side effects from opioid analgesics or adjuvant medications. For example, patients may develop inadequately controlled pain due to opioid toxicity or opioid resistance. Such syndromes are characterized by increasing opioid tolerance, dose limiting side effects, or rapid opioid titration with diminishing analgesia.

This presentation will discuss the role for nonopioid parenteral analgesics such as ketamine and lidocaine in managing refractory cancer pain. This involves a review of the role of ketamine as an analgesic, co-analgesic and as an agent for reversing opioid tolerance. During this presentation we will review an audit of 150 patients at The Ottawa Hospital who received combined intravenous opioid and ketamine infusions between January and December 2006. In this presentation the action of lidocaine as an analgesic and its role in managing refractory neuropathic pain syndromes will be discussed as will the use of parenteral lidocaine administered continuously for extended periods of time.

\section{$16 \mathrm{C}$}

ABOVE AND BEYOND THE WHO LADDER

Catherine Smyth MD PhD FRCPC

Department Anesthesiology, The Ottawa Hospital, Assistant

Professor, University of Ottawa; Medical Director, The Ottawa Hospital Pain Clinic, Ottawa, Ontario

The focus of this presentation will be on the interventional techniques used by Anesthesiologists to manage pain. Many of the anesthesia techniques used in the acute pain setting can be applied to the cancer patient's pain. These include: neuraxial techniques, continuous regional nerve block catheters and neurolytic nerve block procedures (i.e. celiac plexus block). Utilizing radiographic images, our case based approach will illustrate the indications and contraindications of various interventional techniques. The rationale for choosing an intrathecal versus an epidural approach will be discussed. Furthermore, a retrospective review of the neuraxial techniques and regional nerve block techniques utilized between January 2004 and December 2007 at The Ottawa Hospital will be presented.

We will conclude the workshop by seeking participant input on our proposed algorithm for selecting the most appropriate modality for an individual with refractory cancer pain.

\section{1:30 AM - HOT TOPICS IN PAIN RESEARCH}

\section{7}

\section{STUDENT PRESENTATIONS}

Chair: Brian Cairns PhD RPh

Associate Professor \& Canada Research Chair, Faculty of Pharmaceutical Sciences, University of British Columbia, Vancouver, British Columbia Speakers: Daron G Owen MSc, Kelly B Smith MA, Sara Ahola MA, lohn Robertson MSc 
17A

FUNCTIONAL NEUROIMAGING OF TONIC MUSCULAR PAIN Daron G Owen $\mathrm{MSc}^{1,2}$, Collin Clarke $\mathrm{MD}^{3}$, Frank S Prato $\mathrm{PhD}^{1,2,4}$, Keith S St Lawrence PhD ${ }^{1,2,5}$

${ }^{1}$ Imaging Program, Lawson Health Research Institute; ${ }^{2}$ Department of Medical Biophysics, The University of Western Ontario;

${ }^{3}$ Department of Anesthesia and Perioperative Medicine, The University of Western Ontario; ${ }^{4}$ Department of Nuclear Medicine, St Joseph's Hospital; ${ }^{5}$ Robarts Research Institute; London, Ontario AIM: Imaging regional changes in cerebral blood flow (CBF) has been used extensively to identify brain areas associated with the experience of pain. Most imaging studies have involved superficial pain, such as contact heat, of brief duration (less than 30 seconds), whereas clinical pain is generally prolonged and arises from deep tissues [1,2]. The aim of this study was to use perfusion MRI to identify neuronal activation caused by experimental tonic (sustained) muscular pain [3].

METHODS: Eleven healthy subjects were imaged during 10 minutes of baseline (no pain) followed by 15 minutes of pain from the intramuscular infusion of hypertonic saline (HS) $(5 \% \mathrm{NaCl})$ into the left forearm. After an initial $0.5 \mathrm{ml}$ bolus, the infusion rate was adjusted to maintain a subjective pain intensity rating of $7 / 10$.

RESULTS: The largest CBF increases occurred during the 1 st 2.5 min of pain and these were observed bilaterally in the insula, thalamus, putamen, anterior and middle cingulate, as well as contralateral S2 and ipsilateral middle frontal gyrus. Initial significant decreases in CBF were seen mainly in the parietal cortex and S1. Levels of CBF increase and decrease both dissipated over time.

CONCLUSIONS: Perfusion MRI is able to track changes in regional $\mathrm{CBF}$ that occur during prolonged tonic muscular pain. The initial bolus of HS caused the greatest CBF increases. Interestingly, these increases diminished over the following $10 \mathrm{~min}$ even though the subjective pain intensity ratings remained greater than $5 / 10$. This may be due to a decrease in the unpleasantness of the pain.

\section{FOOTNOTES/REFERENCES}

1. Shipton EA, Tait B. Flagging the pain: preventing the burden of chronic pain by identifying and treating risk factors in acute pain. Eur J Anaesthesiol 2005;22(6):405-12.

2. Schreckenberger M, Siessmeier T, Viertmann A, Landvogt C, Buchholz HG, Rolke R, Treede RD, Bartenstein P, and Birklein F. The unpleasantness of tonic pain is encoded by the insular cortex. Neurology 2005;64:1175-1183.

3. Owen DG, Bureau Y, Thomas AW, Prato FS, and St. Lawrence KS. Quantification of pain-induced changes in cerebral blood flow by perfusion MRI. Pain 2007 doi:10.1016/j.pain.2007.06.021

\section{B}

\section{THINKING THE WORST? FEAR- AND PAIN-RELATED} THOUGHTS AMONG WOMEN WITH VULVODYNIA

Kelly B Smith MA ${ }^{1}$, Caroline F Pukall PhD ${ }^{1}$, Susan Chamberlain MD $^{2}$, Corrie Goldfinger BA $^{1}$, Evelyne Gentilcore-Saulnier BSC $^{3}$, Sasha Segal $\mathbf{B A}^{\mathbf{1}}$

${ }^{1}$ Department of Psychology, Queen's University; ${ }^{2}$ Department of Obstetrics and Gynecology, Queen's University; ${ }^{3}$ PT School of Rehabilition Therapy, Queen's University, Kingston, Ontario

AIM: Little is known about women's perceptions of and reactions to vulvar pain. The purpose of this study was to examine fear of pain and negative pain-related cognitions among women with vulvodynia.

METHODS: This study is part of an ongoing project. To date, 37 women with vulvodynia and 48 control women have participated. Women underwent a telephone screening to assess eligibility, and eligible participants completed online questionnaires, including the short-form Pain Anxiety Symptoms Scale to assess overall fear of pain and subscales of anxiety, avoidance, fearful thinking, and physiological responses, and the Pain Catastrophizing Scale to assess overall catastrophizing. Women with vulvodynia completed these measures twice, once in relation to their vulvar pain and once in relation to a regularly experienced non-genital pain; control women completed these measures only once in relation to a regularly experienced form of pain.
RESULTS: Thirty-four women with vulvodynia and 38 control women reported regularly experiencing a non-genital form of pain. In comparison to control women's experiences with non-genital pain, women with vulvodynia reported significantly increased fearful thinking and catastrophizing in relation to vulvar pain only. Within the vulvodynia group, participants reported more fear-related thinking associated with vulvar versus non-vulvar pain.

CONCLUSIONS: These preliminary results suggest that vulvodynia may be associated with maladaptive cognitions. The role that fear-and painrelated thoughts play in women's experiences with vulvodynia, and the implications that such thoughts may have for the management of this condition will be discussed.

\section{FOOTNOTES/REFERENCES:}

Asmundson GJG, Vlaeyen JWS, Crombez G. (2004). Understanding and treating fear of pain. New York: Oxford University Press.

Payne KA, Binik YM, Amsel R, Khalife S. When sex hurts, anxiety and fear orient attention towards pain. European Journal of Pain 2005;9:427436.

\section{C}

\section{DOES THE NFCS DIFFERENTIATE BETWEEN INFANTS EXPERIENCING PAIN-RELATED AND NON-PAIN RELATED DISTRESS?}

\section{Sara Ahola MA}

York University, Toronto, Ontario

AIM: The Neonatal Facial Coding System (NFCS) is widely accepted as a measure of infant pain in known pain-specific contexts. However, if it were able to distinguish between pain and non-pain related distress, it may also be used to determine if pain is present in more ambiguous distress situations. The primary purpose of this study is to explore whether NFCS can differentiate between pain and non-pain related distress.

METHODS: Two groups of 35 infants, either distressed or not distressed prior to injection, were coded using NFCS before and after an immunization. RESULTS: Within-group analyses of infants who were distressed preimmunization suggested that NFCS was not able to discriminate between pain and non-pain related distress. However, between-group analyses showed NFCS discriminated between potential gradations of distress in infants post-immunizations.

CONCLUSIONS: Results suggest that NFCS has the ability to discriminate between intensities of distress but not between pain and non-pain related distress.

\section{D}

\section{FUNCTIONAL IMAGING OF MAGNETIC FIELD THERAPY}

John Robertson $\mathrm{MSc}^{1}$, Julie Weller OSSD ${ }^{2}$, Jean Theberge $\mathrm{PhD}^{1,3}$, Dick J Drost PhD ${ }^{1,3}$, Frank S Prato PhD ${ }^{1,3}$, Alex W Thomas PhD ${ }^{1,3}$ ${ }^{1}$ Bioelectromagnetics Group, Imaging Program, Lawson Health Research Institute, Department of Medical Biophysics, University of Western Ontario; ${ }^{2}$ Department of Psychology, University of Western Ontario, Bioelectromagnetics Group, Imaging Program, Lawson Health Research Institute; ${ }^{3}$ Diagnostic Radiology, St Joseph's Health Care, London, Ontario

AIM: We have previously reported the analgesic effects of a specific pulsed magnetic field in snails, rodents, and humans. Based on the use of headonly exposures in chronic pain patients, we believe that the effect is based on changes in processing within the brain. To determine what these changes might be we have used functional magnetic resonance imaging (fMRI) with normal human volunteers.

METHODS: A Peltier thermode device (Medoc) was affixed to the hypothenar region of the subject's dominant hand. This delivers a noxious heat stimulus $\left(48-51^{\circ} \mathrm{C}\right.$, depending on the subject's individual pain threshold) 10 times, each for 21 seconds in a "boxcar" design within the MRI. The subjects will then be exposed to the analgesic pulsed magnetic field (peak $200 \mu \mathrm{T}$ ), or a sham condition for 15 minutes, after which the fMRI/heat procedure is repeated.

RESULTS: The images were analyzed with Brain Voyager (Brain Innovation). 30 subjects (17 sham, 13 exposed) have been analyzed, and a 
change in pain processing was detected in several brain regions, primarily in the anterior and posterior cingulate cortex. Detailed results will be presented at the conference.

CONCLUSIONS: This study reveals that there are changes in the functional processing of pain following a specific pulsed magnetic field exposure. These results will help improve the future use of magnetic field therapies for pain. Moreover, they are, to the best of our knowledge, the first use of a MRI gradient system specifically as an active therapy device.

\section{1:30 PM - TRAINEE SESSION 204}

\section{8}

\section{HOW TO GET A CIHR DOCTORAL AWARD}

Chair: Melanie Noel MSc

Canadian Pain Society Trainee Representative; Clinical Psychology PhD Student, Dalhousie University, Halifax, Nova Scotia Speakers: C Meghan McMurtry BA (Hons), Clinical Psychology PhD Student, Dalhousie University, Centre for Pediatric Pain Research, IWK Health Centre, Halifax, Nova Scotia; Dominique Lalonde, Head, Program Delivery Division, Research Capacity Development, Canadian Institutes of Health Research, Ottawa, Ontario One of the greatest challenges for trainees is applying for, and obtaining, student fellowships. This trainee session will provide trainees with helpful information from two unique perspectives.

\section{1:30 PM - SLIDE SESSION 205}

\section{9}

\section{SLIDE SESSION}

Chair: Peter MacDougall PhD MD FRCPC

Assistant Professor, Dalhousie University, Department of

Anesthesia and Family Medicine, Halifax, Nova Scotia

Speakers: Pamela Barton BSc(Hon) MD FRCPC, Lesley A Graff PhD, Niklas Schuelert PhD, Post-Doctoral fellow, Gregg Tkachuk PhD, Barry I Sessle BDS MDS BSc PhD DSc (hc) FRSC, Mark A Ware MBBS MRCP MSC

\section{A}

\section{HUMAN RESOURCE REQUIREMENTS IN AN ADULT AMBULATORY INTERDISCIPLINARY CHRONIC PAIN TREATMENT PROGRAM}

\section{Pamela Barton BSc(Hon) MD FRCPC}

Calgary Health Region Chronic Pain Centre, Division of Physical Medicine and Rehabilitation, University of Calgary; Geoffrey Schultz PhD, Calgary Health Region Chronic Pain Centre; John Jarrell MD FRCPC MS, Calgary Health Region Chronic Pain Centre Department of Obstetrics and Gynecology, University of Calgary, Calgary, Alberta

AIM: The purpose of this study was to determine the human resource requirements to treat a chronic pain patient.

METHODS: All patients evaluated (partial or complete) by the Calgary Health Region Chronic Pain Centre between July 1, 2000 and October 31, 2003 and discharged prior to April 30, 2007 were included. Patients were characterized by general demograpics and severity of illness based on a number of standardized measures. Patients were deemed to have completed their programs if they had achieved satisfactory completion of personal goals and/or their pain had 1. resolved, 2. plateaued or 3. they had to leave the program for a variety of reasons. All health care provider time was extracted from the pain centre appointment scheduling database.

RESULTS: 491 patients met study criteria: 175 musculoskeletal pain, 120 headache, 196 female pelvic pain. Their average age was 40 years. $15 \%$ were male and $85 \%$ female. Average pain levels were $6.4 / 10$ (SD 1.8). Each patient received an average of: 42.7 (SD 46.1) direct patient care hours, 11.5 (SD 10.8) indirect patient care hours as well as 25.1 (SD 29.3) group care hours. Average individual professional care hours (direct and indirect) per patient by discipline were: physician 9.3 (SD 9.2), nurse 11.5 (SD 10.5), physical therapist 15.5 (SD 19.2), psychologist 10.2 (SD 14.5) occupational therapist 3.2 (SD 8.4), kinesiologist 3.2 (SD 6.4).

CONCLUSIONS: This is the first documentation of human resource utilization in terms of actual hours of care required to treat a chronic pain population in an ambulatory interdisciplinary setting utilizing a goal oriented, chronic disease model. This is of major relevance to health care administrators in planning such programs.

\section{B}

\section{DO PAIN ANXIETY AND PAIN CATASTROPHIZING CHANGE WITH DISEASE ACTIVITY?}

Lesley A Graff $\mathrm{PhD}^{1}$, John Walker $\mathrm{PhD}^{1}$, Lisa Lix $\mathrm{PhD}^{1}$, Ian Clara $\mathrm{MA}^{2}$, Linda Rogala $\mathrm{RN}^{3}$, Norine Miller $\mathrm{RN}^{3}$, Patricia Rawsthorne $\mathrm{RN}^{3}$, Charles N Bernstein MD $^{4}$

${ }^{1}$ Clinical Health Psychology, Faculty of Medicine; ${ }^{2}$ Psychology, Faculty of Arts; ${ }^{3}$ IBD Clinical and Research Centre; ${ }^{4}$ Internal Medicine, Faculty of Medicine, University of Manitoba, Winnipeg, Manitoba

AIM: The aim of this study was to assess pain anxiety and pain catastrophizing in the context of a chronic health condition, inflammatory bowel disease, which has fluctuating disease activity that includes intense abdominal pain. We evaluated relationships between these variables and a wide range of psychological functioning dimensions in individuals with active and inactive disease. As well, using data gathered at two points, two years apart, we considered the temporal stability of pain anxiety and catastrophizing, and whether there were systematic changes in these variables over time with changes in disease.

METHODS: 310 individuals with IBD, recruited from a population-based IBD registry, provided longitudinal data. Those with active and inactive disease at baseline were grouped according to disease activity at the 2 year point to identify four different disease patterns: active/active, active/inactive, inactive/active and inactive/inactive.

RESULTS: Active disease at baseline was associated with higher pain anxiety and pain catastrophizing. During active disease, pain anxiety was moderately correlated with distress, health anxiety, and neuroticism $(r=.37$ to $.58, \mathrm{p}<.001$ ); pain catastrophizing was only modestly associated with other negative psychological functioning. ANOVAs and subsequent comparisons indicated that pain anxiety decreased over time and catastrophizing did not. Contrary to expectations, change in pain anxiety over time was not different across the disease activity patterns.

CONCLUSIONS: The findings are discussed in the context of other moderating factors as well as disease adaptation for this community-based sample of patients with fluctuating disease and concomitant pain.

\section{C}

\section{ACTIVATION OF CANNABINOID CB2 RECEPTORS REVEALS A PARADOXICAL EFFECT ON JOINT PAIN IN NORMAL AND OSTEOARTHRITIC RAT KNEES}

Niklas Schuelert PhD, Postdoctoral fellow, Jason J McDougall PhD, Associate Professor

University of Calgary, Dept of Physiology and Biophysics, Calgary

Alberta

AIM: The present study examined whether the synthetic cannabinoid-2 (CB2) receptor agonist GW405833 could modulate joint pain in osteoarthritic (OA) rat knee joints.

METHODS: OA was induced in male Wistar rats by intra-articular injection of $3 \mathrm{mg}$ sodium monoiodo-acetate with a recovery period of 14 days. Mechanonociceptor activity was determined electrophysiologically by noxious rotation of the knee joint both before and following close intraarterial injection of GW405833 (10-12, 10-10, 10-8 mol). Pain behavioural experiments were also carried out in $\mathrm{OA}$ animals to examine the effect of GW405833 (10-6 mol, i.artic.) on hindlimb weight distribution and tactile allodynia as measured by von Frey hair algesiometry.

RESULTS: In control joints, application of GW405833 significantly reduced nociceptor firing rate in $42 \%$ of recorded afferent nerve fibres during 
noxious joint rotation. In the OA joint, however, a desensitizing effect of GW405833 was observed in only $5 \%$ of recorded fibres with the majority of fibres showing increased neuronal activity. Intra-articular injection of GW405833 into OA knee joints exacerbated hindlimb incapacitance and increased mechanical allodynia.

CONCLUSIONS: These findings indicate that peripheral injection of GW405833 into control knees reduces joint nociception. Conversely in OA knee joints, activation of CB2 receptors causes increased nociceptor activity and a heightened pain response. These paradoxical effects of GW405833 indicate that peripheral modulation of CB2 receptors is contraindicated for the treatment of OA pain.

\section{D}

\section{INCREASED PAIN ACCEPTANCE MEDIATES OUTCOMES RELATED TO IMPROVEMENTS IN CATASTROPHIZING, FEAR AND SELF-EFFICACY}

Gregg Tkachuk PhD ${ }^{1}$, Marc Woods PhD $^{2}$

${ }^{1}$ Department of Clinical Health Psychology, University of Manitoba and Pan Am Pain Clinic, Winnipeg Regional Health Authority, Winnipeg, Manitoba; ${ }^{2}$ Chronic Pain Centre, Saskatoon Health Region, Saskatoon, Saskatchewan

AIM: Chronic pain acceptance has been defined as a willingness to experience pain (without attempting to change it) in the service of engaging in valued life directions (McCracken, 2005). Acceptance has accounted for more variance in functioning than cognitive control variables (McCracken \& Eccleston, 2003; 2005) and as much as catastrophizing (Vowles et al., 2007), in hierarchical regression analyses. This study examined whether changes in acceptance mediated relationships between changes in catastrophizing, fear, self-efficacy and outcomes related to interdisciplinary chronic pain treatment.

METHODS: One hundred thirty-eight chronic pain patients (64\% female, mean age 46 years, 77\% Musculoskeletal Pain) completed a semi-structured functional interview (Canadian Occupational Performance Measure) as well as the Multidimensional Pain Inventory, Beck Depression Inventory-II, Pain Catastrophizing Scale, Tampa Scale of Kinesiophobia, Chronic Pain SelfEfficacy Scale, and Chronic Pain Acceptance Questionnaire before and after a 6-week, half-day interdisciplinary treatment program.

RESULTS: Changes in acceptance mediated relationships between changes in catastrophizing and functioning $(\mathrm{R} 2=0.074 ; \mathrm{Z}=-2.09, \mathrm{p}=0.04)$, catastrophizing and depression $(R 2=0.10 ; Z=2.39, p=0.02)$, fear and functioning $(\mathrm{R} 2=0.081 ; \mathrm{Z}=-2.10, \mathrm{p}=0.036)$, fear and depression $(\mathrm{R} 2=0.153$; $\mathrm{Z}=2.11, \mathrm{p}=0.035)$, self-efficacy and functioning $(\mathrm{R} 2=0.079 ; \mathrm{Z}=2.05$, $p=0.040)$, and self-efficacy and depression $(R 2=0.137 ; Z=-2.19, p=0.028)$. CONCLUSIONS: These results suggest that acceptance plays a facilitative role in overall adjustment to chronic pain that subsumes other important processes, and therefore, would appear to be important to address directly in chronic pain treatment.

\section{$19 \mathrm{E}$}

\section{P2X RECEPTOR-INDUCED INCREASE IN EXCITATORY NEUROTRANSMISSION IN THE TRIGEMINAL SUBNUCLEUS CAUDALIS (VC) IS NMDA RECEPTOR- DEPENDENT AND INVOLVES PKC}

\section{Ernest A lennings PhD ${ }^{1}$, Barry J Sessle BDS MDS BSc PhD DSc (hc)} FRSC $^{2}$

${ }^{1}$ Department Anatomy \& Cell Biology, University of Melbourne, Parkville, Vic, 3010, Australia; ${ }^{2}$ Faculty of Dentistry, University of Toronto, Toronto, Ontario

AIM: The majority of trigeminal small-diameter nociceptive primary afferent fibres innervating craniofacial tissues terminate in $V_{c}$. We have previously shown in vivo that central sensitisation of nociceptive neurons in deep $\mathrm{V}_{c}$ laminae can be induced by purinergic (P2X) receptor agonists and blocked by P2X antagonists applied in this area (Chiang et al., 2005). Our in vitro studies indicate that P2X agonists act presynaptically to facilitate Vc excitatory neurotransmission (Jennings et al., 2006). This study aimed to test if these $\mathrm{P} 2 \mathrm{X}$ receptor processes involve NMDA receptor mechanisms and PKC.
METHODS: Sprague-Dawley rat pups (9-16 days) were anaesthetised with halothane, decapitated and horizontal slices $(250 \mu \mathrm{m})$ were cut from the caudal brainstem. Whole-cell patch-clamp recordings (voltage clamped at $-70 \mathrm{mV}$ ) were made from $\mathrm{V}_{\mathrm{c}}$ neurons.

RESULTS: An increase in excitatory neurotransmission in deep $V_{c}$ laminae, as reflected in an increase in mEPSC rate, was induced by the ATP analogue \&\#61537; ,\&\#61538; -methylene- ATP (\&\#61537; ,\&\#61538; meATP, $30 \mu \mathrm{M}, \mathrm{n}=14 ; \mathrm{P}<0.01$ ) but was blocked (no change in mEPSC rate or amplitude; $n=7 ; P>0.1)$ following superfusion of the NMDA antagonist AP5 $(40 \mu \mathrm{M})$. In other brain areas, phosphorylation of NMDA receptors through PKC has been shown to potentiate glutamatergic neurotransmission, so we tested if \&\#61537;,\&\#61538;-meATP activated an intracellular kinase cascade that altered NMDA receptor function in Vc. \&\#61537;,\&\#61538;-meATP $(30 \mu M)$ applied in the presence of the kinase inhibitor staurosporine $(2 \mu \mathrm{M})$ did not affect mEPSC rate $(n=7$; $\mathrm{P}>0.9$ ).

CONCLUSIONS: These results suggest that P2X receptor-mediated central sensitisation in deep laminae of $\mathrm{V}_{\mathrm{c}}$ is mediated via NMDA receptors and involves PKC.

\section{F}

\section{THE EFFECTS OF NABILONE ON INSOMNIA IN FIBROMYALGIA: RESULTS OF A RANDOMIZED} CONTROLLED TRIAL

Mark A Ware MBBS MRCP MSc ${ }^{1}$, Mary-Ann Fitzcharles MD FRCPC $^{1}$, Lawrence Joseph PhD $^{2}$, Kim West RN ${ }^{1}$, Yoram Shir MD ${ }^{1}$ ${ }^{1}$ Pain Clinic, McGill University Health Centre; ${ }^{2}$ Department of Epidemiology and Biostatistics, McGill University, Montreal, Quebec

AIM: Fibromyalgia (FM) is a chronic pain syndrome with generalized tender points. Insomnia affects over $75 \%$ of patients with FM, and tricyclic antidepressants are the mainstay of treatment. Cannabis has been used by patients with FM to help sleep. We evaluated nabilone, a synthetic cannabinoid, for insomnia in FM.

METHODS: We conducted a randomized double-blind active control equivalency crossover trial to compare nabilone $(0.5-1.0 \mathrm{mg}$ qHS) to amitriptyline $(10-20 \mathrm{mg}$ qHS) in FM patients with chronic insomnia. Subjects received each drug for two weeks with a two-week washout. The primary outcome was sleep quality using the Insomnia Severity Index (ISI) and the Leeds Sleep Evaluation Questionnaire (LSEQ); secondary outcomes included pain, mood, quality of life and adverse events (AEs).

RESULTS: Thirty-one subjects were enrolled and 29 completed the trial (26 female, mean age 49.5y). While sleep was improved by both nabilone and amitriptyline, nabilone was superior to amitriptyline (ISI difference $=3.2,95 \%$ CI 1.2-5.3). Nabilone was marginally better on the restfulness LSEQ sleep quality scale (difference $=0.5(0.0-1.0)$ but not on wakefulness (difference $=0.3(-0.2,0.8)$ ). Adverse events were all mildmoderate and were more frequent with nabilone (102) than amitriptyline (53). Most common AEs for nabilone were dizziness (10), nausea (9) and dry mouth (7).

CONCLUSIONS: Nabilone is effective in improving sleep in patients with FM and is well tolerated. Low dose nabilone given once daily at night may be considered as an alternative to amitriptyline. Longer trials are needed to determine the duration of effect and to characterize long-term safety. 


\section{1:30 PM - SESSION 206}

\section{0}

\section{NEUROMODULATION THERAPY}

Chair: Alex W Thomas PhD

CIHR Industry Chair in Bioelectromagnetics, Lawson Health

Research Institute, Department of Medical Biophysics, Schulich

School of Medicine and Dentistry University of Western Ontario, London, Ontario; V-P Research, Fralex Therapeutics Inc., Toronto,

Ontario

Speakers: Alex W Thomas PhD, Arthur A Pilla PhD,

Tracy Cameron PhD

BRIEF DESCRIPTION: Neuromodulation by electrical and magnetic stimulation is one of the newest and most controversial pain medicine practices. Deep brain stimulation (DBS), spinal cord stimulation, vagal nerve stimulation, and transcutaneous nerve stimulation may have common mechanisms but they target very different areas to elicit pain relief. Spinal Cord Stimulation (SCS), Pulsed Radio Frequency Magnetic Field (PRF), and complex neural pulses (CNP) also offer a method of neuromodulation, but differ greatly in both proposed mechanisms and targets. Here, experts in SCS, PRF, and CNP will present some of their latest data.

\section{A}

FUNCTIONAL IMAGING OF PULSED MAGNETIC FIELD NEUROMODULATION

Alex W Thomas PhD

CIHR Industry Chair in Bioelectromagnetics, Lawson Health Research Institute, Department of Medical Biophysics, Schulich School of Medicine and Dentistry, University of Western Ontario, London, Ontario; V-P Research, Fralex Therapeutics Inc., Toronto, Ontario

\section{B \\ CLINICAL USE OF NON-INVASIVE PULSED RADIO FREQUENCY TO REDUCE POST-OPERATIVE PAIN \\ Arthur A Pilla PhD \\ Professor Emeritus, Department of Orthopaedics, Mount Sinai School of Medicine, New York; Chairman, IVIVI Scientific Advisory Board, IVIVI Technologies, Northvale, New Jersey, USA}

\section{C \\ NEUROMODULATION FOR THE TREATMENT OF PAIN PAST AND PRESENT \\ Tracy Cameron PhD \\ V-P Scientific Affairs, Advanced Neuromodulation Systems, St. Jude Medical, Plano, Texas, USA \\ Spinal cord stimulation (SCS) has been established as a safe, effective, and reversible treatment in a variety of human diseases (Stratton and Smith, 1980; Fall, 1980, 1994; Tanagho et al., 1989). It was originally founded on the assumption that small diameter pain fibers could be blocked by acti- vating the large diameter sensory fiber located primarily in the dorsal columns (Melzack and Wall, 1965; Wall and Sweet, 1967; Shealy et al., 1967). Despite its widespread use the exact mechanism with which it exerts its effect still remains unknown. This presentation will look at the changes that have taken place in the area of SCS with regard to both indi- cations and technologies from its early days until today.}

\section{1:30 PM - SESSION 207}

\section{1}

\section{HYPOGONADISM AND OTHER ENDOCRINE SIDE EFFECTS OF OPIOID THERAPY IN PATIENTS WITH CHRONIC NON- CANCER PAIN}

Chair: Patricia K Morley-Forster MD FRCPC

Speakers: Patricia K Morley-Forster MD FRCPC ${ }^{1}$; Ali Imran MBBS

FRCP(Edin) FRCPC ${ }^{2}$, Stan VanUum MD PhD ${ }^{3}$

1St Joseph's Hospital, Schulich School of Medicine, University of Western Ontario, London, Ontario; ${ }^{2}$ Assistant Professor, Dept of Endocrinology and Metabolism, Dalhousie University, Halifax, Nova Scotia; ${ }^{3}$ Assistant Professor, Dept of Endocrinology, Schulich School of Medicine, University of Western Ontario, London, Ontario

Workshop Objectives:

1. To describe changes in pituitary function known to occur with opioid therapy with a focus on hypogonadism

2. To increase awareness of potential long-term health risks of androgen and estrogen suppression

3. To address monitoring and treatment options and issues related to hypogonadism in the chronic pain patient on opioids

Learning Objectives:

The participant will:

1. Understand that several changes in pituitary function occur with OT, the most significant being hypogonadism

2. Be able to describe clinical and laboratory parameters relevant to monitoring for hypogonadism

3. Be able to identify those patients requiring preventive therapy for osteoporosis

\section{A}

HYPOGONADISM AND OTHER ENDOCRINE SIDE EFFECTS OF OPIOID THERAPY IN PATIENTS WITH CHRONIC NONCANCER PAIN

Patricia K Morley-Forster MD FRCPC

St Joseph's Hospital, Schulich School of Medicine, University of Western Ontario, London, Ontario

Opioid therapy (OT) is now widely used for treatment of chronic noncancer pain. However, little information is available on its long-term efficacy or safety. The Chair, Dr Morley-Forster, will provide a brief introduction to the epidemiologic data on frequency and duration of OT in this context as well as RCT data indicating its short-term benefits.

\section{B}

HYPOGONADISM AND OTHER ENDOCRINE SIDE EFFECTS OF OPIOID THERAPY IN PATIENTS WITH CHRONIC NONCANCER PAIN

\section{Ali Imran MBBS FRCP(Edin) FRCPC}

Assistant Professor, Dept of Endocrinology and Metabolism, Dalhousie University, Halifax, Nova Scotia

Dr Imran will present an overview of changes in pituitary function induced by OT and will present known data on the effect of opioids on the hypothalamic-pituitary-adrenal and HP-gonadal axis. These effects include growth hormone deficiency, hypocortisolism and a reduction in sex hormones (hypogonadism). Both heroin drug use and methadone maintenance have been associated with low serum testosterone levels since the 1970's (1). More recent studies on chronic pain patients receiving opioid therapy either orally or intrathecally have shown that these treatments cause hypogonadism (2,3). Most studies in patients taking chronic opioids have demonstrated low, or inappropriately normal, levels of LH and FSH along with low serum testosterone and/or estradiol. This supports a central hypothalamic cause for the hypogonadism. Other studies have indicated changes in peripheral steroid metabolism due to opioid use. Currently, the occurrence of hypogonadism during chronic opioid therapy is underappreciated. 
21C

HYPOGONADISM AND OTHER ENDOCRINE SIDE EFFECTS OF OPIOID THERAPY IN PATIENTS WITH CHRONIC NONCANCER PAIN

Stan VanUum MD PhD

Assistant Professor, Dept of Endocrinology, Schulich School of Medicine, University of Western Ontario, London, Ontario

Hypogonadism may result in decrease of sexual function, well-being and mood, and over a long time also in a decrease of bone mineral density. The latter may result in osteoporosis and thus in an increased risk of osteoporosisrelated fractures (4). Specific data on the occurrence of these negative consequences of hypogonadism are scarce for this patient group and no guidelines address the related issues encountered in clinical practice. Dr VanUum will present original data on the incidence of hypogonadism, decreased sexual function and decreased bone mineral density from prospective studies on chronic pain patients on OT for at least one year. He wil also address monitoring and treatment options for hypogonadism and osteoporosis in these patients.

\section{FOOTNOTES/REFERENCES}

1. Azizi F, Vagenakis AG, Longcope C, Ingbar SH, Braverman LE. Decreased serum testosterone concentration in male heroin and methadone addicts. Steroids 1973;22-467.

2. Abs R, Verhelst J, Maeyaert J, Van Buyten JP, Opsomer F, et al. Endocrine Consequences of Long-Term Intrathecal Administration of Opioids. Journal of Clinical Endocrinology \& Metabolism 2000;85(6):2215-22.

3. Daniell HW. Hypogonadism in Men Consuming Sustained-Action Oral Opioids. J Pain 2002;3(5):377-84.

4. Riggs BL, Khosla S, Melton LJ 3rd. Primary Osteoporosis in Men: Role of Sex Steroid Deficiency. Mayo Clin Proc 2000;75:S46-50.

4:00 PM - PLENARY SESSION 208

\section{2}

\section{CHRONIC PAIN SELF MANAGEMENT PROGRAMS: RESEARCH AND DISSEMINATION}

Chair: Michael H McGillion RN PhD

Assistant Professor, The Lawrence S Bloomberg Faculty of Nursing, University of Toronto, Toronto, Ontario

Speakers: Michael H McGillion RN PhD, Sandra LeFort RN PhD, lennifer Stinson RN PhD

\section{A}

\section{INTRODUCTION TO CHRONIC PAIN SELF-MANAGEMENT} Michael H McGillion RN PhD

Assistant Professor, The Lawrence S Bloomberg Faculty of Nursing, University of Toronto, Toronto, Ontario

Chronic pain remains an important and ubiquitous public health concern that seriously affects people's everyday lives. Up to $39 \%$ of communitydwelling adults in Western countries suffer from chronic pain, posing a major negative impact on health-related quality of life (HRQL), or the perceived burden of the pain, with respect to functional abilities, psychological well-being and relationships [1,2]. Despite the high prevalence and deleterious impact of chronic pain, access to timely and appropriate care remains problematic. This plenary provides a brief history and overview of the concept of self-management, discussion of seminal pain selfmanagement work in the United States and self-efficacy as a key mechanism behind successful pain self-management, and detailed examples of current self-management research programs for specific adult and child chronic pain problems in Canada including chronic non-cancer pain, stable angina and juvenile idiopathic arthritis (JIA). Key implications for pain self-management practice, research and dissemination will also be discussed.

\section{B}

\section{SELF-MANAGEMENT OF CHRONIC NON-CANCER PAIN}

Sandra LeFort RN PhD

Director and Associate Professor, School of Nursing, Memorial

University of Newfoundland, St. John's, Newfoundland

An estimated $19-29 \%$ of the adult population suffers from chronic noncancer pain, resulting in deep distress, disability, and disruptions in individual and family functioning. LeFort will present the results of a 1998 single-site randomized controlled trial (RCT), involving 110 participants, in order to determine the efficacy of the Chronic Pain SelfManagement Program (CPSMP) for improving pain and functional status-related outcomes. The CPSMP was designed to enhance selfefficacy via a standardized small-group intervention format (7-9 patients per group), delivered by a nurse facilitator, in 2 hours weekly, over 6 weeks. This trial found that the CPSMP resulted in significant improvements in pain, dependency on others, sense of vitality, various aspects of role functioning, life satisfaction and self-efficacy and resourcefulness to manage pain in the short-term (i.e. 3 months post intervention). Results of a subsequent multi-site effectiveness trial of the CPSMP (across 3 Canadian provinces) will also be presented. This 2003-2004 trial ( $\mathrm{n}=279)$ demonstrated that the positive effects on mental health and resourcefulness of the initial CPSMP trial were retained short-term when the program was delivered by generic health care providers in the context of their regular workload. These benefits were retained long-term in a sub-sample of participants who were followed for 12 months post-intervention.

\section{C}

\section{SELF-MANAGEMENT OF CHRONIC STABLE ANGINA}

\section{Michael H McGillion RN PhD}

Assistant Professor, The Lawrence S Bloomberg Faculty of Nursing, University of Toronto, Toronto, Ontario

Cardiac pain arising from chronic stable angina (CSA) pectoris is a ubiquitous and cardinal symptom of ischemic heart disease, characterized by pain or discomfort in the chest, upper abdomen, back, arm(s), shoulders, neck, jaw and/or teeth. This condition is distressing, often resulting in recurrent pain episodes, poor general health, impaired role functioning, activity restriction, and reduced capacity for self-care. Recent prevalence data suggest that more than $6,500,000$ Americans may be living with CSA. McGillion will present results of a recent RCT $(n=130)$ that examined the impact of a low-cost 6-week angina self-management program, entitled The Chronic Angina Self-Management Program (CASMP), on HRQL, self-efficacy and resourcefulness to self-manage angina pain. The CASMP significantly improved physical functioning, general health, angina frequency, angina stability, and self-efficacy to manage disease in the short term. Results of a recent meta-analysis that examined the overall effectiveness of self-management interventions for improving symptoms, HRQL and psychological well-being for CSA patients will also be presented. Seven RCTs, involving 949 participants across 7 countries were reviewed. Self-management training was found to reduce angina and the need for nitroglycerine by approximately 3 and 4 times per week respectively, in the short-term. Major improvements in physical functioning and general health status were also found. The overall ability of self-management to improve psychological well-being for CSA patients remains unknown. The ability of self-management programs to improve psychological wellbeing, cut illness-related costs, and reduce various aspects of health service utilization continue to be major research priorities.

\section{D}

\section{HARNESSING THE POTENTIAL OF THE INTERNET: DEVELOPMENT OF A WEB-BASED SELF-MANAGEMENT PROGRAM FOR CHILDREN WITH ARTHRITIS}

\section{lennifer Stinson RN PhD}

CIHR Post-Doctoral Fellow, Clinician Scientist, Centre for Nursing, Hospital for Sick Children, Toronto, Ontario

JIA is the most common chronic pediatric rheumatic disease, affecting between 7 and 148 children per 100,000 person years in Western Europe and North-America. This disease can negatively impact HRQL; its course 
is unpredictable and children commonly experience pain, joint swelling, stiffness and fatigue that may restrict physical and social interactions. E-health technologies can offer an innovative approach to improving the health service delivery and acceptability of self-management interventions for adolescents with JIA. A recent Cochrane systematic review of interactive health communication applications or internet based interventions found that they were effective for improving knowledge and helping patients to feel more socially supported. Stinson will review findings from a qualitative study that explored the self-management needs of adolescents with JIA, and determined the acceptability of a web-based self-management approach for this patient group. Participants expressed the need for more information, clear self-management strategies, and meaningful social supports to better manage their JIA. They believed that web-based interventions were a promising avenue to improve accessibility and availability of these interventions. Next steps of this program of research will also be presented including the development and usability testing of: Teens Taking Charge-Managing Arthritis On-line web-based intervention. This intervention provides information, self-management strategies and social support. These preliminary steps will lay the foundation for a multi-centre RCT in order to test the effectiveness of the program for reducing pain and improving HRQL outcomes for adolescents with JIA.

\section{4:00 PM - SESSION 209}

\section{3}

\section{USING QUANTITIVE SENSORY TESTING (QST) IN CHRONIC PAIN EVALUATION: FROM RESEARCH TO CLINICAL PRACTICE}

\section{Chair: Pam Squire MD CCFP}

Clinical Assistant Professor, University of British Columbia, Lions Gate Hospital, North Vancouver, British Columbia Speakers: Pam Squire MD CCFP ${ }^{1}$, Serge Marchand $\mathrm{PhD}^{2}$, Mark Ware MBBS MRCP(UK) MS $\mathrm{c}^{3}$

${ }^{1}$ Clinical Assistant Professor, University of British Columbia, Lions Gate Hospital, North Vancouver, British Columbia; ${ }^{2}$ Professor titulaire, Chaire en douleur UQAT-UdeS, Universite de Sherbrooke, Faculte de medicine, neurochirurgie; ${ }^{3}$ MUHC Pain Clinic, Departments of Anesthesia and Family Medicine, McGill University, Montreal, Quebec

BRIEF DESCRIPTION: This workshop reviews the data on mechanistic approaches for the diagnosis and treatment of chronic pain. The focus will be on the utilization of quantitative sensory testing (QST) to characterize the somatosensory phenotype of patients with neuropathic pain. The review will include current research paradigms but will primarily focus on how to utilize and incorporate simple bedside QST into everyday clinical practice. The session will be interactive and there will be extensive opportunity for discussion of practical issues.

Learning Objectives:

1. Review and update of the evaluation of neuropathic pain with a focus on pain measurement. This will review current tools for the quantification of symptoms of neuropathic pain and discuss methods of eliciting signs of neuropathic pain using bedside quantitative sensory testing (QST). The rationale for performing these evaluations will be discussed. (Squire)

2. Discuss the neurophysiological basis of QST and the evidence for the utility of QST in guiding treatment options in complex pain disorders. (Marchand)

3. Discuss practical clinical issues in performing QST in the clinical environment. A bedside demonstration will be performed using the suggested tools. (Ware)
23A

EVALUATING NEUROPATHIC PAIN: WHERE ARE WE NOW AND WHERE ARE WE GOING

\section{Pam Squire MD CCFP}

Clinical Assistant Professor, University of British Columbia, Lions Gate Hospital, North Vancouver, British Columbia

Review and update of the evaluation of neuropathic pain with a focus on pain measurement. This will review current tools for the quantification of symptoms of neuropathic pain and discuss methods of eliciting signs of neuropathic pain using bedside quantitative sensory testing (QST). The rationale for performing these evaluations will be discussed.

\section{B}

\section{THE NEUROPHYSIOLOGIC BASIS OF QST AND ITS CLINICAL RELEVANCE}

Serge Marchand PhD

Professor titulaire, Chaire en douleur UQAT-UdeS, Universite de Sherbrooke, Faculte de medicine, neurochirurgie, Montreal, Quebec

Discuss the neurophysiological basis of QST and the evidence for the utility of QST in guiding treatment options in complex pain disorders.

\section{C}

\section{A PRACTICAL DEMONSTRATION OF BEDSIDE QUANTITATIVE SENSORY TESTING}

Mark Ware MBBS MRCP(UK) MSc

MUHC Pain Clinic, Departments of Anesthesia and Family Medicine, McGill University, Montreal, Quebec

Discuss practical clinical issues in performing QST in the clinical environment. A bedside demonstration will be performed using the suggested tools.

$$
\text { 4:00 PM - SESSION } 210
$$

\section{4}

\section{MECHANISMS AND TREATMENT OF CHRONIC} CRANIOFACIAL PAIN

Chair: Brian Cairns PhD RPh

Associate Professor \& Canada Research Chair, Faculty of

Pharmaceutical Sciences, University of British Columbia,

Vancouver, British Columbia

Speakers: Mark Drangsholt DDS MPH PhD, Eli Whitney DDS

FRCDC, Brian Cairns PhD RPh

BRIEF DESCRIPTION: Chronic craniofacial pain affects a significant proportion of the North American population. For example, temporomandibular disorders (TMDs), for which the principal complaint is pain in the temporomandibular joint and/or masticatory muscles has been estimated to affect about $10 \%$ of the adult population. The pathophysiology underlying the development of craniofacial pain syndromes, such as TMD, burning mouth syndrome and trigeminal neuralgia is still not well understood, complicating the diagnosis and treatment of these conditions. Further, most chronic craniofacial pain conditions, such as TMDs, are more common in women and men, although the reasons for sex-related differences are not well understood. This objective of this workshop is to provide information on putative mechanisms and current diagnosis and treatment for chronic craniofacial pain with a focus on TMDs.

Learning Objectives:

1. Discuss approaches to standardize and validate diagnostic measures for chronic craniofacial pain.

2. Review biomechanical and pharmacological interventions for chronic craniofacial pain and assess their value in therapy.

3. Describe basic research aimed at developing animal models of TMD and investigating how sex-related differences in pain perception from deep craniofacial tissues may occur. 


\section{A}

EVALUATION OF DIAGNOSTIC CRITERIA FOR CHRONIC CRANIOFACIAL PAIN

Mark Drangsholt DDS MPH PhD

Assistant Professor, University of Washington School of Dentistry, Seattle, Washington, USA

Advances in understanding of trigeminal neuropathic pain, TMD-related pains and other chronic craniofacial pain will be discussed with an emphasis on how these advances are changing our understanding of the pathology of these conditions and aiding in improving their diagnosis and treatment.

\section{B}

\section{THERAPEUTIC INTERVENTIONS FOR CHRONIC CRANIOFACIAL PAIN \\ Eli Whitney DDS FRCDC}

Assistant Professor, Faculty of Dentistry, The University of British Columbia, Vancouver, British Columbia

Biomechanical and pharmacological interventions for chronic craniofacial pain will be discussed and their value in therapy assessed from an evidencebased perspective. Indications for multidisciplinary management will be presented.

\section{C}

ANIMAL MODELS OF MYOFASCIAL TMD: WHAT ARE THEY REVEALING ABOUT CRANIOFACIAL PAIN PROCESSING

Brian Cairns PhD RPh

Associate Professor \& Canada Research Chair, Faculty of Pharmaceutical Sciences, University of British Columbia, Vancouver, British Columbia

Animal models of non-inflammatory masticatory muscle and temporomadibular joint pain will be presented. Evidence for sex-related differences in the peripheral processing of nociceptive input and the mechanisms that may underlie these effects will be explored.

\section{SCIENTIFIC PROGRAM DAY TWO FRIDAY, MAY 30, 2008}

\section{7:30 AM - JANSSEN-ORTHO INC. SPONSORED SYMPOSIUM}

\section{5}

\section{PAIN MANAGEMENT IN THE ERA OF NSAID} CONTROVERSIES

Chair: Sol Stern BSc MSc MCFP

Chairman of Palliative Care, Halton Healthcare Services, Oakville, Ontario

Speaker: Philip A Baer MDCM FRCPC FACR, VP of the Ontario Rheumatology Association; Chair of the OMA Section of Rheumatology, Toronto, Ontario

BRIEF DESCRIPTION: A Canadian rheumatologist discusses musculoskeletal pain management, in light of recent controversies regarding NSAIDs, including the withdrawal of three COXIBs.

Learning Objectives:

Attendees will gain a better understanding of:

1. Canadian pain statistics.

2. Potential adverse effects of NSAIDs and COXIBs.

3. Guidelines on musculoskeletal pain management.

4. The role of opioids, particularly tramadol, in MSK pain.

\section{8:45 AM - KEYNOTE SPEAKER}

\section{6}

SURGERY AND PERSISTENT PAIN

Chair: Michael H McGillion RN PhD

Assistant Professor, The Lawrence S Bloomberg Faculty of Nursing, University of Toronto, Toronto, Ontario

Speaker: Judy Watt-Watson RN PhD

University of Toronto, Lawrence S Bloomberg Faculty of Nursing,

Toronto, Ontario, 2008 Canadian Pain Society Distinguished Career Award Winner

BRIEF DESCRIPTION: Evidence will be presented that unrelieved pain after cardiac surgery is common and after discharge it may persist with a neuropathic component. Management strategies involving clinicians and organizations will be discussed.

\section{0:30 AM - PLENARY SESSION 301}

\section{7}

\section{DIET AS AN ANALGESIC MODALITY}

Chair: Yoram Shir MD

Associate Professor, Department of Anesthesia, Faculty of Medicine, McGill University, Montreal, Quebec

Speakers: Yoram Shir MD, Robin B Kanarek, John Pereira

BRIEF DESCRIPTION: Diet and dietary ingredients have been extensively investigated for their beneficial role in a variety of ailments. Although less well studied as an analgesic modality, there is a growing body of evidence showing that dietary ingredients may be analgesic in experimental animals and humans. In animals, basic dietary ingredients such as carbohydrates, amino-acids and fatty acids, as well as dietary supplements and trace elements have the potential to attenuate acute and chronic nociception. For example, sweet-tasting foods possess analgesic properties, probably through altered responsiveness to opiate analgesia; specific foods, like dietary soy, attenuate persistent nociception in models of neuropathic and cancer pain. Preliminary data in humans indicate that dietary ingredients like omega-3 fatty acids and fiber and foods such as soy, cherries and green tea possess analgesic properties. Dietary ingredients could exert their effect through multiple mechanisms including manipulating the production and function of excitatory amino-acids and cytokines and by changing the incorporation of phospholipids into peripheral nerve membranes. The participants in this plenary session will review the evidence of dietary mediated analgesia in animals and humans and will outline possible future research directions in this field.

\section{A}

DIETARY ANALGESIA: AN OVERVIEW

Yoram Shir MD

Associate Professor, Department of Anesthesia, Faculty of Medicine, McGill University, Montreal, Quebec

\section{B}

THE ROLE OF SWEET TASTING FOODS IN MODULATING OPIOID ANALGESIA

Robin B Kanarek

John Wade Professor, Department of Psychology, Tufts University, Medford, Massachusetts, USA

\section{C}

INFLAMMATORY PATHWAYS AND DIET: PUTTING OUT THE FIRE

lohn Pereira

Chronic Pain Centre, Calgary Health Region, Calgary, Alberta 
10:30 AM - SESSION 302

\section{8}

PAIN AND CULTURE IN CANADA

Chair: Angela Mailis-Gagnon MD MSC

Director, Comprehensive Pain Program, Toronto Western Hospital, Toronto, Ontario

Speakers: Angela Mailis-Gagnon MD MSc ${ }^{1}$, Annie Hsieh $\mathrm{MA}^{2}{ }^{2}$ Dean A Tripp PhD $^{3}$

${ }^{1}$ Director, Comprehensive Pain Program, Toronto Western Hospital, Toronto; ${ }^{2}$ Pain Research Lab, Department of Psychology, Queen's University; ${ }^{3}$ Associate Professor, Departments of Psychology, Anesthesiology \& Urology, Queen's University, Kingston, Ontario

WORKSHOP OBJECTIVE: The influence of culture and ethnicity on pain perception and expression has been the focus of research since the 1950s. Both in the laboratory and clinical settings, cultural or ethnic groups seem to react or express pain differently despite no differences in the discrimination of painful stimuli. Culture relates to the learned and shared values, beliefs, norms and practices of a particular group. Diseaserelated beliefs are interactive product of cultural background, socioeconomic status, educational level and sex. Canada is a truly multicultural country, given the percentage of foreign born (national average 18\%, Ontario average 27\%, Toronto average 44\%, 2001 Stats Canada). Therefore, it is important that health professionals are able to function under cross-cultural circumstances as all patient-provider encounters have the potential for cross-cultural misunderstanding.

Dr A Hsieh will present a study examining the role of psychological variables in pain responses between Chinese and Euro-Canadians, while pain threshold, tolerance and intensity were measured during a cold pressor task. Dr D Tripp will discuss methodological issues overlooked in CrossCultural Research as applied to pain. Dr A Mailis Gagnon will present data from a large outpatient pain clinic demonstrating that patients of different cultural backgrounds present with different types of complaints and will discuss the difficulties and necessity of conducting ethnocultural research.

Learning Objectives:

By the end of the workshop the participants will

a) acquire broad understanding of the importance of ethnocultural issues in pain perception and expression and

b) be guided to appropriate clinical research projects in order to increase cultural competence.

\section{A}

\section{ETHNOCULTURAL AND SEX CHARACTERISTICS OF PATIENTS ATTENDING A TERTIARY CARE PAIN CLINIC IN TORONTO}

\section{Angela Mailis-Gagnon MD MSc}

Director, Comprehensive Pain Program, Toronto Western Hospital, Toronto, Ontario

Since ethnocultural and sex characteristics affect pain perception and expression, the study looked at the presentation of a consecutive series of 1242 patients seen for the first time in a tertiary pain clinic. Diagnostic categorization of pain disorders utilized the 2000 Diagnostic and Statistical Manual of Mental Disorders, 4th edition- text revision, while place of birth and language spoken at home were chosen as ethnic identifiers. Canadian born patients constituted $58.6 \%$ of the clinic population (similar to Stats Canada data for the Greater Toronto Area), while in regards to foreign born, 2 out of 3 visible minority groups were under-represented and European immigrants were over-represented. Women outnumbered men but presented with lower levels of physical pathology, particularly in two visible minority groups. Finally, European immigrants were 10-15 years older upon their first presentation to the pain clinic as compared to all other groups (Canadian and foreign born) despite the highest incidence of physical painful disorders. We will discuss the limitations of the study, the difficulties conducting ethnocultural research and the need for well designed studies to assist in the development of a "biocultural" model in order to develop cultural competence and to guide diagnostic and treatment decisions.

\section{B}

\section{ETHNIC DIFFERENCES IN ACUTE PAIN EXPERIENCE FOR CHINESE AND EUROPEAN CANADIANS}

\section{Annie Hsieh MA}

PhD student, Pain Research Lab, Department of Psychology, Queen's University, Kingston, Ontario

Culture has a significant impact on how pain is experienced. Clinical and laboratory studies show ethnic differences in pain responses, and ethnic disparities in pain are gaining increased research attention (Campbell et al., 2005). Nevertheless, ethnic differences in pain response and the contribution of psychological factors in such differences is a neglected research area. Moreover, most of these studies have examined African Americans and Hispanics with little published with Asian samples. The present study examined differences in pain reporting between Chinese and EuroCanadians, exploring the role of psychological variables (i.e., catastrophizing, beliefs about appropriate pain behaviours). Prior to completing a cold pressor task, 57 Chinese and 66 Euro-Canadian undergraduates were administered the Pain Catastrophizing Scale and the Appropriate Pain Behaviour Questionnaire. Pain threshold, pain tolerance, and pain intensity were measured during the cold pressor task. Affective and sensory pain were measured immediately post-immersion using the Short Form-McGill Pain Questionnaire. Compared to Euro-Canadians, Chinese found pain behaviours (e.g. grimacing, crying, and talking about pain) in the presence of others less appropriate. While there was no ethnic difference in pain threshold, Chinese participants displayed lower pain tolerance and reported higher pain intensity, sensory pain and affective pain than European Canadians. Additionally, Chinese participants reported higher pain catastrophizing, which partially mediated the ethnic difference in pain responses. The clinical implications of the study will be discussed.

\section{C}

OVERLOOKED METHODOLOGICAL ISSUES IN CROSSCULTURAL RESEARCH

\section{Dean A Tripp PhD}

Associate Professor, Departments of Psychology, Anesthesiology \& Urology, Queen's University, Kingston, Ontario

With the advancement of the "global village", health psychology theories based on predominantly North American samples need to be examined for their utility in other cultures. The pain literature has made advances in our understanding of cultural differences in pain over the past 10 years but few studies have examined Asian samples and in particular Chinese or Chinese-Canadian samples. In conducting studies utilizing cross-cultural comparisons, researchers must be cognizant of the potential pitfalls of an ethnically biased methodology during participant assessment. Although there are many topics of relevance, the major issues of foreign language translation (e.g., closed ended questions - Pain Catastrophizing Scale, likert-type anchors - McGill Pain Questionnaire, reliability and construct equivalences - SEM), single item self-report assessments of ethnicity often used in pain and quality of life research, and on other factors that may act as confounds with culture or country of origin (e.g., differences in response tendencies or biases) are worthy of consideration and discussion. There are several research strategies that can be employed to help rule out competing hypotheses in cross cultural research. For example, although translations are often performed on a back translation process (i.e., translated into another language and then back again to the original), these can be examined with monolinguals within separate countries or cultures. One could also employ a double design where the translated and non-translated work is provided to bilinguals. Further discussion will also comment on multi-cultural scale development as a potential method and musings of our current emerging line of research. 


\section{0:30 AM - SESSION 303}

\section{9}

\section{INTERVENTIONAL PAIN}

Chair: Norman Buckley

Associate Professor and Chair, Department of Anesthesia, Michael G DeGroote School of Medicine, McMaster University, Hamilton, Ontario

Speakers: Edvin Koshi MD FRCPC, Gordon Ko MD CCFP FRCPC DABPM, Ian Beauprie

BRIEF DESCRIPTION: Interventional pain management is a crucial part of a multi-disciplinary pain management strategy for chronic noncancer pain. Multiple modalities of intervention have been developed to address spinal, muscular and neuropathic pain.

Learning Objectives:

1. The goals of the workshop are to review a broad spectrum of interventional pain management techniques including facet denervation, neuromodulation and botulinum toxin.

\section{A}

\section{A REVIEW OF DIAGNOSTIC LUMBAR FACET JOINT BLOCKS}

Edvin Koshi MD FRCPC

Assistant Professor, Departments of Anesthesia and Neurosurgery, Dalhousie University, Halifax, Nova Scotia

An evidence-based approach to the management of facet joint mediated non-cancer spinal pain. This will include a review diagnostic criteria for facet pain and the techniques for injection and denervation of the joint.

\section{B}

\section{BOTULINUM TOXIN (BOTOX) FOR THE MANAGEMENT} OF CHRONIC NON-CANCER PAIN

Gordon Ko MD CCFP FRCPC DABPM

Medical Director, Physiatry Pain Clinic, Sunnybrook Health Sciences Centre, Department of Medicine, University of Toronto; Founding Director, Canadian Society for Neurotoxins in Pain, Toronto, Ontario

An evidence based approach to the utilization of botox for the management of chronic non-cancer pain. This will include a review of indications, patient selection and techniques for use of botox.

\section{C}

NEUROMODULATION (NERVE STIMULATOR) TECHNIQUES FOR MANAGEMENT OF PAIN

lan Beauprie

Professor, Departments of Anesthesia and Neurosurgery, Dalhousie University, Halifax, Nova Scotia

An evidence and experience based approach to neuromodulation for neuropathic pain. Who is a good candidate and what can be done for them?

\section{2:30 PM - PFIZER CANADA INC. SPONSORED SYMPOSIUM}

\section{0}

\section{CENTRAL NEUROPATHIC PAIN}

Chair: Christine Short FRCPC

Department of Medicine, Division of Physical Medicine and Rehabilitation, QEII Health Sciences Centre; Assistant Professor, Dalhousie University, Department of Physical Medicine and Rehabilitation; Medical Director, Neurorehabilitation Program, QEII Health Sciences Centre; Vice-chair Canadian Paraplegic Association, Nova Scotia; Medical Advisor, Action Atlantic, Halifax, Nova Scotia

Speakers: Christine Short FRCPC, Department of Medicine, Division of Physical Medicine and Rehabilitation, QEII Health Sciences Centre; Assistant Professor, Dalhousie University, Department of Physical Medicine and Rehabilitation; Medical Director, Neurorehabilitation Program, QEII Health Sciences Centre; Vice-chair Canadian Paraplegic Association, Nova Scotia; Medical Advisor, Action Atlantic, Halifax, Nova Scotia; Cory Toth MD FRCPC, Neurologist and Neuroscientist, Department of Clinical Neurosciences, Hotchkiss Brain Institute, Foothills Medical Complex, Director of the Neuropathic Pain Clinic, Calgary, Alberta;

Martin Katzman, Clinic Director, Stress, Trauma, Anxiety Rehabilitation and Treatment Clinic; Staff Psychiatrist, Centre for Addiction and Mental Health-Clarke Division; Assistant Professor, Department of Psychiatry, University of Toronto; Assistant Professor, Northern Ontario School of Medicine, Department of Psychology and the Department of Community Health, Lakehead University; Co-Chair, Scientific Advisory Board, Anxiety Disorders Association of Canada/Association Canadienne des Troubles Anxieux, Toronto, Ontario

BRIEF DESCRIPTION: This symposium will cover the definition of central neuropathic pain, including the various models, the management of patients with central neuropathic pain (the difficulty of treating the patients, the additional/associated symptoms such as anxiety and depression) and treatment options.

Learning Objectives:

1. Definition of central Neuropathic pain, including the various models (ex. spinal cord injury, MS, etc)

2. Management of patient with central Neuropathic pain (the difficulty of treating the patients, the additional/associated symptoms associated to the disease such as anxiety and depression)

3. Treatment Options

\section{2:00 PM - SESSION 304}

\section{1}

PAIN RESOURCE PROGRAMS: IMPROVING KNOWLEDGE TRANSLATION IN PAIN MANAGEMENT

Chair: Lori Palozzi RN MScN APN

The Hospital for Sick Children, Toronto, Ontario

Speakers: Lori Palozzi RN MSCN APN, Salima Ladak RN MN APN, Nancy Schuttenbeld RN MN

WORKSHOP OBJECTIVE: To discuss the development and implementation of a Pain Resource Program from three different perspectives. Nursing and interprofessional models have been developed in both academic and rural hospital settings, involving both single and multiple sites. This workshop will specifically address how the various programs were developed, implemented and evaluated. Suggestions for designing and sustaining success of the pain resource role will be discussed.

Learning Objectives:

The Learner will: 
1. Describe various approaches to the development and implementation of a pain resource program.

2. Compare and contrast the models with respect to type of setting, program design, content material, and role evaluation.

3. Discuss the challenges and opportunities that exist in rural and urban teaching facilities involving a multi site and multidisciplinary approach.

4. Have an understanding of the variables affecting implementation and challenges in sustainability of the role.

5. Be encouraged to reflect on how these models may be applicable to their practice.

\section{$31 \mathrm{~A}$}

THE DEVELOPMENT OF A PAIN RESOURCE NURSE ROLE: A KNOWLEDGE TRANSLATION STRATEGY TO IMPROVE PAIN MANAGEMENT IN CHILDREN

Lori Palozzi RN MScN APN

The Hospital for Sick Children, Toronto, Ontario

BACKGROUND: It is well recognized that a variety of knowledge translation strategies are required to bring about sustained changes in knowledge and behaviour related to pain assessment and management. One approach to facilitate knowledge transfer is the development of Pain Resource Nurses. While PRN programs and roles share similarities, there is little understanding about how the PRN role would fit at The Hospital for Sick Children. In particular, there is little known about the specific skills, attributes and qualities of the PRN which can influence the uptake of knowledge into practice.

PURPOSE: To describe the Pain Resource Nurse Role from the perspective of nurses and non-nurse health care professionals.

METHODS: In this descriptive exploratory study, focus group methodology will be used to answer the following questions: (1) What are the perceived qualities and essential components of the pain resource nurse role? (2) What are the views of nurses and non-nurse health care professionals on the potential benefits and barriers of implementing a PRN role on a general hospital unit?

Following Research Ethics Board approval and consent, participants will be recruited consecutively into a variety of focus groups including staff nurses, advance practice nurses, clinical managers and unit physicians, and pain service physicians. Data from tape-recorded, semi-structured interviews will be transcribed and analyzed using content analysis.

The focus of the workshop will be to discuss preliminary findings and to discuss strategies to develop stakeholder involvement in preparation for a PRN program.

\section{B}

\section{IMPROVING PAIN MANAGEMENT PRACTICE THROUGH CAPACITY BUILDING: EXPERIENCE OF THE PAIN RESOURCE NURSE ROLE (PRN) IMPLEMENTATION Salima Ladak RN MN APN \\ Toronto General Hosital, University Health Network, Toronto, Ontario}

Learning Objectives:

1. Understand factors influencing implementation of the PRN role within a multi-site quaternary care teaching facility

2. Understand variables affecting sustainability of this role

DESCRIPTION \& AIM: Despite recent advances in pain research and knowledge development, there is a fundamental knowledge deficit among health care practitioners in the assessment and management of pain. One strategy to address this issue has been the implementation of the Pain Resource Nurse (PRN) Role. Although the PRN program is cited as an effective method for improving pain management practices, there is not a clear understanding of the most effective process for role implementation and the factors that may affect sustainability of the role.

METHODS: University Health Network (UHN), a tri-site, quaternary care teaching hospital in Toronto implemented a 4-day PRN Program. Eighty-four registered nurses received education, which focused on the assessment, prevention and management of pain. Participants implemented their PRN role by facilitating the translation of evidence-based pain management knowledge into nursing practice. A qualitative descriptive study design using focus group interviews was used to answer the following questions: What was the experience of the PRN during role implementation? What barriers and enablers affected the implementation of this role?

RESULTS \& CONCLUSIONS: Organizational support, integration within the interdisciplinary team and organizational role awareness were key themes highlighted in the focus group results. This workshop will describe how UHN used the PRN role to foster practice-related change and enhance current knowledge of evidence-based pain management.

\section{$31 \mathrm{C}$}

\section{THE DEVELOPMENT AND IMPLEMENTATION OF AN INTERPROFESSIONAL PAIN RESOURCE PROGRAM} Nancy Schuttenbeld RN MN

River Valley Health, Fredericton, New Brunswick

PURPOSE: The purpose of the Pain Resource Program was to develop an interdisciplinary team of health care professionals with up to date knowledge and skills in pain management. These individuals would function both as a resource and change agent in disseminating information, interfacing with nurses, physicians, and other health care providers to facilitate quality pain management.

METHODS: The program was designed and delivered in an interdisciplinary manner that included evidence based interventions, and explored roles, responsibilities, challenges and opportunities for health care providers regarding pain management. Senior management supported the program, and the Acute Pain Resource Nurses group that had evolved into a multidisciplinary Regional Pain Care Committee selected content to meet the pain education needs of our health care team. The program involved three days of education and interactive learning as well as attendance at the Annual Clinical Day in Pain Management.

PROGRAM EVALUATION: Program evaluation occurred in three phases. A follow up day took place in January 2007 with all participants to discuss pain projects, implementation of the role, and clinical pain management issues. Evaluations of the program were completed by participants with suggestions for future programs.

Follow up contact and support was provided over the next several months to all participants regarding the pain projects and the advocate/resource role. Lastly, the Regional Pain Care Committee reviewed the program from a broader perspective addressing strengths and weaknesses of the program and outcomes on a Regional perspective with consideration for future pain resource programs.

\section{2:00 PM - SESSION 305}

\section{2}

\section{ACUTE ON CHRONIC PAIN MANAGEMENT - WHERE DO WE START?}

Chair: Jennifer Stinson RN PhD

CIHR Post-Doctoral Fellow, Clinician Scientist, Centre for Nursing, Hospital for Sick Children, Toronto, Ontario

Speakers: Sandra Robinson MN ACNP, Toronto Western Hospital, University Health Network, Toronto, Ontario; Patti Kastanias MSC APN, Toronto Western Hospital, University Health Network, Toronto, Ontario

BRIEF DESCRIPTION: The overall aim of this workshop is to provide an opportunity for participants to strategize and develop solutions for the assessment and management of acute-on-chronic pain in the postoperative opiate tolerant patient.

Learning Objectives:

1. To review the implications of acute-on-chronic pain and its impact on the postoperative patient.

2. To provide a forum for participants to strategize for the assessment and management of acute-on-chronic pain in the post-operative, opiate tolerant patient.

3. To highlight an innovative approach to manage pain in this patient population. 
4. To provide an opportunity for participants to critically and creatively assess structures, processes, and resources in their own institution.

As many of us are aware, management of post-operative pain in the acute care setting continues to present significant challenges despite many advances over the last two decades in our knowledge of pain pathophysiology, the development of new analgesics, and the proliferation of clinical practice guidelines. An even greater challenge lies with the post-operative management of patients with preexisting, persistent pain and high opioid requirements. How and when do you begin to manage acute-on-chronic pain in this opiate tolerant population? Who is best suited to do these assessments and develop management plans - surgeons, Preadmit staff nurses, pharmacists, pain management advanced practice nurses, anesthesiologists? At our quaternary care, multi-site teaching hospital, we recently developed both a screening tool and an assessment tool that are used to create a pre, intra and post-operative pain management plan during the preadmit visit - before the surgery. This workshop will use a case-based, interactive format to discuss the issues, strategies and next steps for the assessment and management of acute-on-chronic pain in the post-operative opiate tolerant patient. We will present our successes and challenges and engage the audience in a debate of this, frequently controversial, topic.

Workshop Format:

1. Case study: A patient with persistent pain and high opioid requirements. Participants to work for $10-15$ minutes to examine the current practices at their respective institutions in the management of this patient population.

2. Introduction of TWH Pre-admission Opioid Screening Tool and TWH Pre-admission Pain Assessment Tool and reveal the TWH experience.

3. Discussion/debate: Next steps, best practices, barriers and facilitators to implementation.

\section{2:00 PM - SESSION 306}

\section{3}

WHEN ALL IS SAID AND DONE: STRATEGIES FOR THE LONG-TERM CARE OF PATIENTS WITH CHRONIC NONCANCER PAIN REFRACTORY TO ALL EXISTING THERAPY Chair: Saifee Rashiq MB MSc FRCPC

Speakers: Peggianne Mackenzie RN, Multidisciplinary Pain Centre, University of Alberta; Saifee Rashiq MB MSc FRCPC,

Multidisciplinary Pain Centre, University of Alberta; Bruce Dick $\underline{\mathrm{PhD}}$, Multidisciplinary Pain Centre, University of Alberta; $\underline{\text { Claude }}$ Roberto PhD, Multidisciplinary Pain Centre, University of Alberta, Chronic Pain Association of Canada, Edmonton, Alberta

WORKSHOP OBJECTIVE: To describe a unique Canadian pain management program which sets out to care for and advance the quality of life of persons whose chronic pain has proved refactory to all measures.

Learning Objectives:

The participant will:

1. Critically examine his/her own definition of when further attempts to reduce the intensity of chronic pain are futile

2. Reflect on what he/she usually does with patients who do not respond positively to the treatments that he/she usually administers

3. Learn about a novel approach to the care of these patients which addresses their unique needs

4. Learn how the objectives of this program are co-linear with the views espoused by an acknowledged expert in the self-management of chronic pain

\section{A}

LOW BACK PAIN FOR 8 YEARS IN A 48 YEAR OLD MAN... Peggianne Mackenzie RN Multidisciplinary Pain Centre, University of Alberta, Edmonton, Alberta

Chronic non-cancer pain often fails to respond to all available treatment modalities. Little is written about the role that health care providers can or should play in the subsequent part of such persons' lives. Contemporary models of chronic pain acknowledge the complex interaction between the physical, psychological, social and other spheres of the subject's life, but most pain treatments act only in one sphere. We will begin the session by hearing a description of a prototypical patient seen in a referral pain management centre. His history, physical examination and a list of the things that have been tried to ameliorate his pain will be given, and the audience will be engaged in a discussion about what might be done next, from a practical point of view, if he were a real patient of theirs.

\section{B}

MY WHOLE LIFE HURTS...

Saifee Rashiq MB MSc FRCPC

Multidisciplinary Pain Centre, University of Alberta, Edmonton, Alberta

The point at which a pain state can be said to be truly refractory varies widely. Indeed, in health systems with unrestricted access to pain therapists, such a state may never be acknowledged, as each practitioner tries new (or even previously unsuccessful) treatments. Some of these treatments may actually worsen the pain, or relieve pain only temporarily or at the expense of adverse effects, resulting in a net loss of function. Therapists are often reluctant to declare that nothing more can be done in any given case, and may choose to continue what they suspect to be futile treatments in order to avoid dashing the patient's hope of relief or seeming to reject the sufferer. Sending the patient onto another therapist merely restarts the cycle. We'll examine the full impact of pain on this person's life, what his needs are, what the needs of society and the health care system are, which of these needs can be met, to what extent existing pain treatment can meet them, and the shortcomings of existing treatment approaches.

\section{$33 \mathrm{C}$ \\ THE 'LIFE DESPITE PAIN' PROGRAM \\ Bruce Dick PhD}

Multidisciplinary Pain Centre, University of Alberta, Edmonton,

\section{Alberta}

An alternative viewpoint is to accept the pain state as being beyond treatment but simultaneously to regard the patient as being worthy of ongoing care, either merely as an act of compassion, or in order to try and improve (or retard reductions in) function and quality of life. We will describe our respone to this challenge, the 'Life Despite Pain' program from the Multidisciplinary Pain Centre at the University of Alberta This is an open-ended chronic pain management program focused on goals other than pain intensity reduction, based on the biopsychosocial model of complex illness. We will also describe the program's effect on function and quality of life using validated instruments, and conduct mock-ups of key components of the program for the audience to participate in.

\section{D}

\section{AT PEACE WITH PAIN}

\section{Claude Roberto PhD}

Multidisciplinary Pain Centre, University of Alberta, Edmonton, Alberta

Dr Roberto, whose personal experience of chronic pain permits her to speak with authority on its impact, will draw on her experience and published works to lead a discussion of what the respective goals of everyone involved with a chronic pain patient (patient, spouse, health professional..) should be, and how this can best be achieved with the resources that are available

\section{FOOTNOTES/REFERENCES:}

http://www.med.ualberta.ca/uofapain/LDP.htm

Roberto CM, Sussman PS. At Peace with Pain, 1st edition. 2007.

Victoria BC, Trafford Publishing. ISBN1-4120-7073-2 


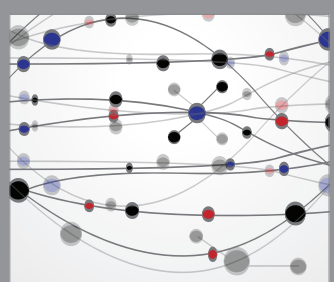

The Scientific World Journal
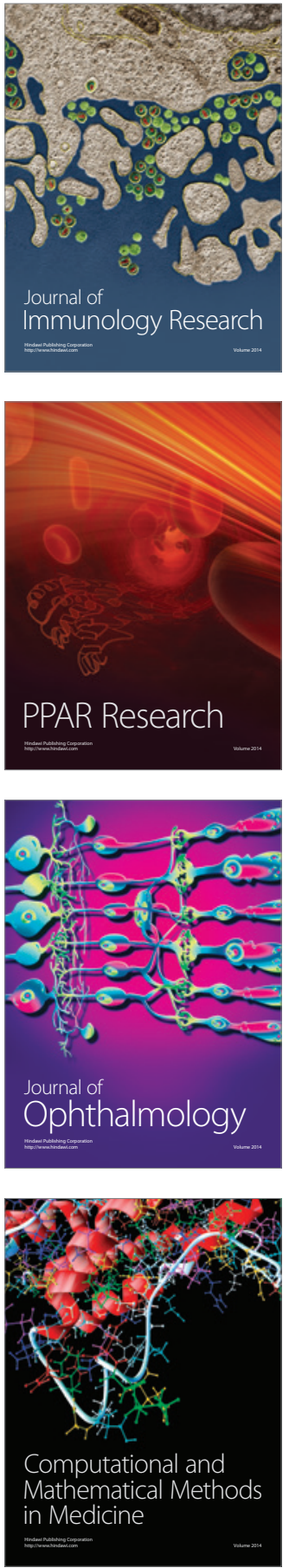

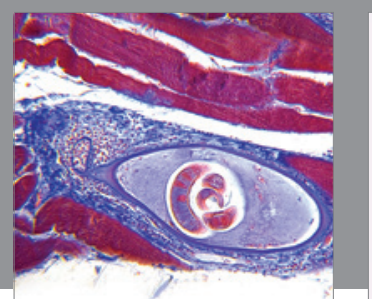

Gastroenterology Research and Practice

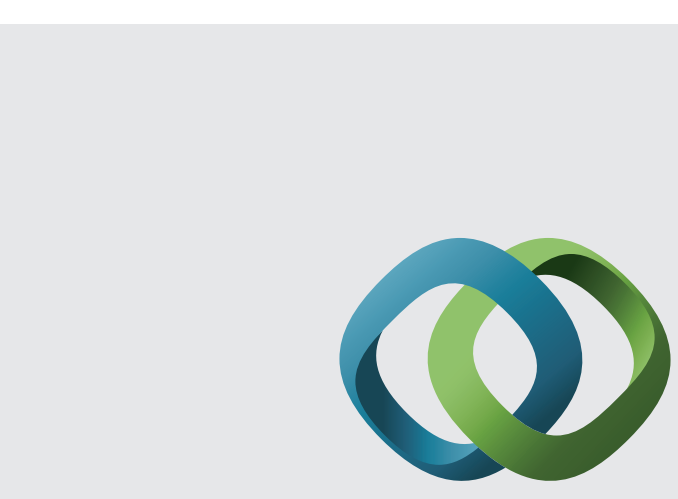

\section{Hindawi}

Submit your manuscripts at

http://www.hindawi.com
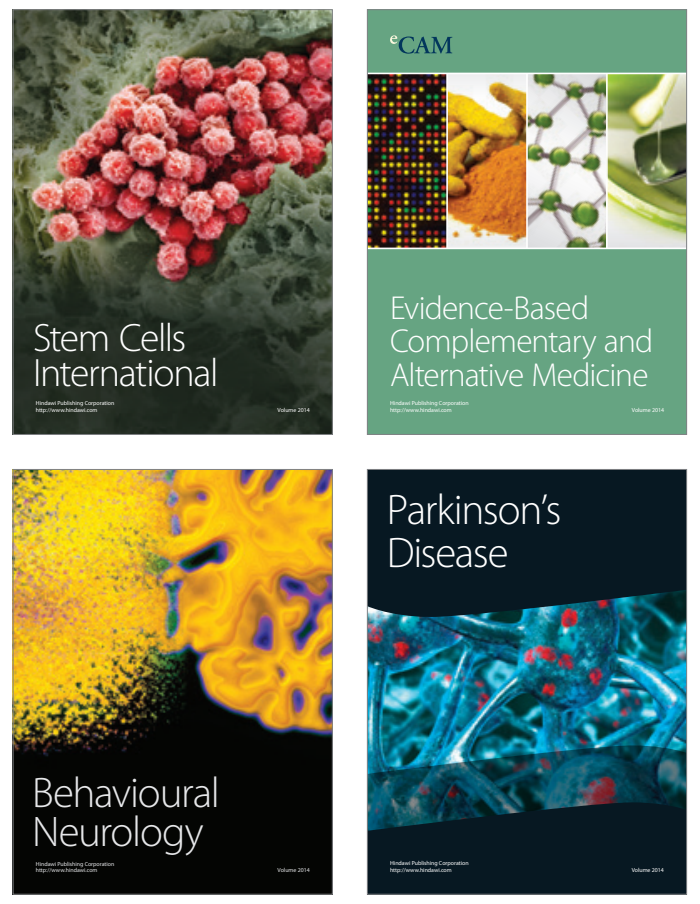
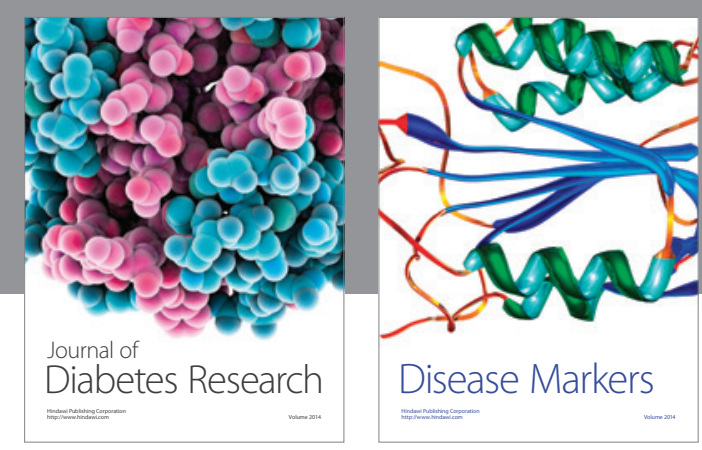

Disease Markers
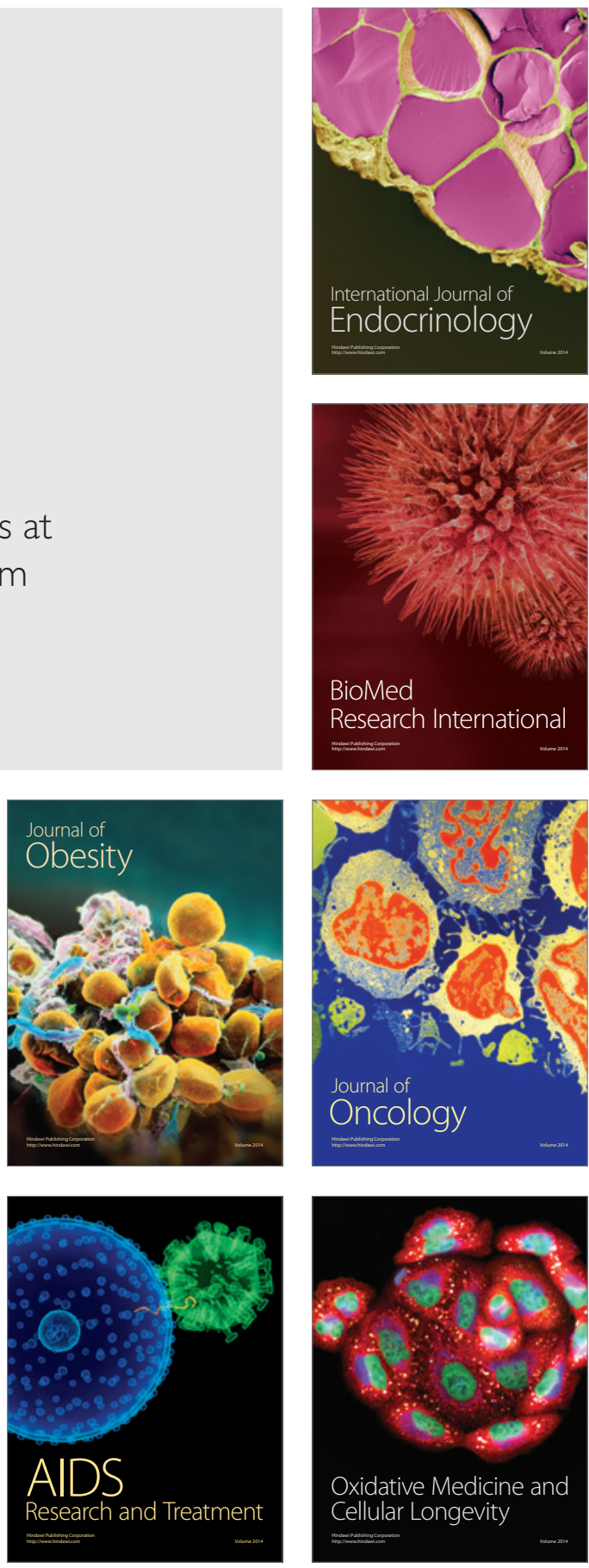